\title{
Leipzig Ice Nucleation chamber Comparison (LINC): intercomparison of four online ice nucleation counters
}

\author{
Monika Burkert-Kohn ${ }^{1}$, Heike Wex ${ }^{2}$, André Welti ${ }^{2}$, Susan Hartmann ${ }^{2}$, Sarah Grawe ${ }^{2}$, Lisa Hellner ${ }^{2}$, Paul Herenz ${ }^{2}$, \\ James D. Atkinson ${ }^{1}$, Frank Stratmann ${ }^{2}$, and Zamin A. Kanji ${ }^{1}$ \\ ${ }^{1}$ Institute for Atmospheric and Climate Science, ETH Zurich, Universitätstrasse 16, 8092 Zurich, Switzerland \\ ${ }^{2}$ Leibniz Institute for Tropospheric Research (TROPOS), Permoserstrasse 15, 04318 Leipzig, Germany
}

Correspondence to: Monika Burkert-Kohn (monika.burkert@env.ethz.ch) and Zamin A. Kanji (zamin.kanji@env.ethz.ch)

Received: 20 April 2017 - Discussion started: 27 April 2017

Revised: 18 August 2017 - Accepted: 18 August 2017 - Published: 29 September 2017

\begin{abstract}
Ice crystal formation in atmospheric clouds has a strong effect on precipitation, cloud lifetime, cloud radiative properties, and thus the global energy budget. Primary ice formation above $235 \mathrm{~K}$ is initiated by nucleation on seed aerosol particles called ice-nucleating particles (INPs). Instruments that measure the ice-nucleating potential of aerosol particles in the atmosphere need to be able to accurately quantify ambient INP concentrations. In the last decade several instruments have been developed to investigate the icenucleating properties of aerosol particles and to measure ambient INP concentrations. Therefore, there is a need for intercomparisons to ensure instrument differences are not interpreted as scientific findings.

In this study, we intercompare the results from parallel measurements using four online ice nucleation chambers. Seven different aerosol types are tested including untreated and acid-treated mineral dusts (microcline, which is a K-feldspar, and kaolinite), as well as birch pollen washing waters. Experiments exploring heterogeneous ice nucleation above and below water saturation are performed to cover the whole range of atmospherically relevant thermodynamic conditions that can be investigated with the intercompared chambers. The Leipzig Aerosol Cloud Interaction Simulator (LACIS) and the Portable Immersion Mode Cooling chAmber coupled to the Portable Ice Nucleation Chamber (PIMCA-PINC) performed measurements in the immersion freezing mode. Additionally, two continuous-flow diffusion chambers (CFDCs) PINC and the Spectrometer for Ice Nuclei (SPIN) are used to perform measurements below and just above water saturation, nominally presenting deposition nucleation and condensation freezing.
\end{abstract}

The results of LACIS and PIMCA-PINC agree well over the whole range of measured frozen fractions (FFs) and temperature. In general PINC and SPIN compare well and the observed differences are explained by the ice crystal growth and different residence times in the chamber. To study the mechanisms responsible for the ice nucleation in the four instruments, the FF (from LACIS and PIMCA-PINC) and the activated fraction, AF (from PINC and SPIN), are compared. Measured FFs are on the order of a factor of 3 higher than AFs, but are not consistent for all aerosol types and temperatures investigated. It is shown that measurements from CFDCs cannot be assumed to produce the same results as those instruments exclusively measuring immersion freezing. Instead, the need to apply a scaling factor to CFDCs operating above water saturation has to be considered to allow comparison with immersion freezing devices. Our results provide further awareness of factors such as the importance of dispersion methods and the quality of particle size selection for intercomparing online INP counters.

\section{Introduction}

Ice crystal formation in the atmosphere changes cloud physical and optical properties, thus influencing the lifetime of clouds, and is important for precipitation formation (e.g., Lohmann and Feichter, 2005; Boucher et al., 2013; Mülmenstädt et al., 2015). The importance of ice nucleation mechanisms and the properties of aerosol particles acting as socalled ice-nucleating particles (INPs), which are seed particles necessary for ice nucleation to occur on, are not suffi- 
ciently understood (see, e.g., Vali et al., 2015; Kanji et al., 2017) and demand further investigation to accurately parameterize atmospheric ice formation in climate models (DeMott et al., 2010; Phillips et al., 2013). Laboratory measurements on well-characterized aerosol particles and ambient observations improve our understanding of atmospheric ice nucleation processes and INP abundance in the atmosphere. This helps to quantify the role of different INPs in cloud formation under the conditions commonly found in the atmosphere.

Ice nucleation can occur via different mechanisms, either homogeneously at temperatures $(T)$ lower than $235 \mathrm{~K}$ (e.g., Pruppacher and Klett, 1997) or heterogeneously - catalyzed by an INP that provides a surface for ice to nucleate on at $T>235 \mathrm{~K}$. For heterogeneous ice nucleation, several pathways are distinguished: deposition nucleation, in which water vapor directly deposits on an INP to form ice in water-subsaturated conditions; contact freezing in which ice formation is due to a supercooled cloud droplet colliding with an INP; condensation freezing in which water vapor directly deposits on an INP to form water and/or ice in water-supersaturated conditions, with the existence of liquid water expected but not explicitly observed; and immersion freezing, in which an INP is immersed in a droplet and has attained sufficient supercooling to freeze (e.g., Vali, 1985). While the descriptions given above are followed in this paper, it is discussed that there may not be a difference between condensation and immersion freezing on a process level, when possible freezing point depressions are accounted for (Wex et al., 2014; Vali et al., 2015). Further, Marcolli (2014) suggested that deposition nucleation might in fact be immersion freezing (or homogeneous freezing for $T<235 \mathrm{~K}$ ) of water trapped in pores and cavities at water-subsaturated conditions. Which ice nucleation pathways exist and under what conditions they are relevant in the atmosphere is not fully understood, but has been speculated about and discussed (e.g., Kanji et al., 2017). It has been suggested that immersion mode is the dominant heterogeneous freezing pathway under mixed-phase cloud conditions (e.g., Ansmann et al., 2008; de Boer et al., 2011; Westbrook and Illingworth, 2011). This has been observed in multiple previous studies (see, e.g., Murray et al., 2012; Kanji et al., 2017, and references therein).

Instruments developed to explore ice nucleation for different formation pathways and to measure the concentration of atmospheric INPs fall into two broad categories: offline measurements of aerosol particles collected on filters (e.g., Bigg, 1967; Klein et al., 2010; Conen et al., 2012) or in suspensions (e.g., Hader et al., 2014), which operate on hourly to daily timescales, and online measurements, which are capable of real-time detection of INP concentration with a higher temporal resolution from seconds to minutes. The portable online instruments report INP concentrations for both groundbased (e.g., DeMott et al., 2010; Chou et al., 2011; Garcia et al., 2012; Tobo et al., 2013) and airborne measurements (Rogers et al., 2001a; DeMott et al., 2003a, b, 2010).
Intercomparing instruments in the laboratory under controlled conditions is necessary to characterize their performance for field studies and to compare quantitative reproducibility. Some studies have already investigated the comparability of a number of online and offline instruments on selected aerosol types in a laboratory setting (DeMott et al., 2011; Wex et al., 2014, 2015; Hiranuma et al., 2015; DeMott et al., 2016). Ice nucleation measurements have been conducted with the Leipzig Aerosol Cloud Interaction Simulator (LACIS; Hartmann et al., 2011, immersion mode) in parallel with the Colorado State University continuous-flow diffusion chamber (CSU-CFDC; Rogers et al., 2001b, condensation mode) on size-selected kaolinite particles including samples coated with soluble material (Wex et al., 2014). Lower FFs were measured in LACIS compared to the CSUCFDC, and good agreement was found when particle residence times in the respective instruments were accounted for. Wex et al. (2015) reported measurements on size-selected Snomax ${ }^{\circledR}$ particles with seven instruments including LACIS and the Portable Ice Nucleation Chamber (PINC; Chou et al., 2011). Wex et al. (2015) examined droplets formed on single particles and droplets taken from suspensions containing Snomax ${ }^{\circledR}$. The varying mass of Snomax ${ }^{\circledR}$ per droplet or per particle that was examined by the different instruments was accounted for, and the results agreed within a factor of 3 below $263 \mathrm{~K}$ for all instruments. The PINC measurements at water-supersaturated conditions showed an activation onset temperature (ice fraction larger $\sim 10^{-3}$ ) of $2 \mathrm{~K}$ lower than LACIS, i.e., less ice activity was observed in PINC than for immersion freezing with LACIS. Which factors cause this deviation is not yet explored. DeMott et al. (2015) presented a comparison of the CSU-CFDC to the Aerosol Interaction and Dynamics in the Atmosphere (AIDA) cloud chamber and found agreement only when an empirically determined factor of 3 was applied to the CSU-CFDC data for their measurements of mineral dust (natural samples from Asian, Saharan, and Canary Island sources) at a relative humidity with respect to water $\left(\mathrm{RH}_{\mathrm{w}}\right)$ of $105 \%$. A previous study on immersion freezing (Hartmann et al., 2016) observed differences in the ice nucleation active site density $\left(n_{\mathrm{s}}\right)$ between LACIS and the Immersion Mode Cooling chAmber coupled to the Zurich Ice Nucleation Chamber (IMCA-ZINC; Lüönd et al., 2010) when the same particle type and size was tested at different times and locations. An offset of about 1 order of magnitude in $n_{\mathrm{s}}$ or a temperature shift of 5-6 K for kaolinite particles was found. The fraction of multiple-charged particles as a reason for the deviation was discussed in Hartmann et al. (2016). For the study of Hiranuma et al. (2015) an identical illite-rich mineral dust sample (illite NX) sample was used for their comprehensive intercomparison of 17 ice nucleation instruments and showed an even larger deviation of $8 \mathrm{~K}$ or 3 orders of magnitude in $n_{\mathrm{s}}$ between the different instruments. So far it has not been possible to narrow down whether these discrepancies are inherent to the instruments used or whether other factors such as the particle genera- 
tion techniques and size selection may be the cause since a number of instruments in the Hiranuma et al. (2015) study were not operated in parallel. The discrepancies found in the Fourth International Ice Nucleation workshop with a selection of different instruments and aerosol types (e.g., DeMott et al., 2011; Kanji et al., 2011) emphasized the importance of parallel measurements for a direct comparison of ice nucleation instrumentation. Parallel measurements of specific particle sizes can be used to identify any discrepancies that arise from the ice nucleation methods itself while excluding factors such as differences in aerosol sample, particle generation method, or particle size.

We present a comparison of four online ice nucleation instruments that was performed during the Leipzig Ice $\mathrm{Nu}$ cleation chamber Comparison (LINC) in September 2015, which was hosted by TROPOS, Leipzig. Seven different types of size-segregated aerosol particles were tested for their immersion freezing potential; four were additionally tested for condensation freezing and deposition nucleation. The samples were two untreated mineral dusts (microcline and kaolinite), nitric- or sulfuric-acid-treated microcline particles, and birch pollen washing water of samples from the Czech Republic and Sweden. During long-range transport of aerosol particles in the atmosphere, internal mixing with organics and inorganic constituents can cause a temporary or permanent change in the physicochemical properties of the particles and can decrease their ice nucleation activity as discussed in Kanji et al. (2017). Acid treatment of microcline particles was chosen in the present study to investigate a permanent change after treatment and removal of the acid coating. The selection of aerosol types and sizes known to be ice active at different temperatures allows for a comparison over the full range of detectable frozen and/or activated fractions possible with the instruments.

A simultaneous comparison of LACIS and PIMCA-PINC (Portable Immersion Mode Cooling chAmber coupled to PINC) as well as the direct comparison between PINC and SPIN (the Spectrometer for Ice Nuclei) on size-selected aerosol particles in sub- and supersaturated conditions with respect to water is presented for the first time, allowing the investigation of instrument-specific differences. Furthermore, observations with the four instruments are used for an explicit comparison of immersion freezing of droplets containing single-immersed aerosol particles (LACIS and PIMCA-PINC) to experiments using dry particles above water saturation, in which it is not possible to distinguish between immersion and condensation freezing (SPIN and PINC).

\section{Materials and methods}

\subsection{Aerosol samples and treatment}

The kaolinite sample used in this study is a commercially available product from Fluka (same as Sigma-Aldrich). The microcline sample is a $\mathrm{K}$-feldspar from Minas Gerais in Brazil consisting of $76 \%$ microcline (K-feldspar) and $24 \%$ albite (Na-feldspar) (Augustin-Bauditz et al., 2014). It was provided by the Technical University Darmstadt within the framework of the Ice Nucleation research UnIT (INUIT). For the purpose of wet aerosolization, $2.5 \mathrm{~g}$ of the respective powder material was suspended in $30 \mathrm{~mL}$ of doubledeionized water (Milli-Q, 18.2 M $\Omega \mathrm{cm}$ ). For the acid treatment, $2.5 \mathrm{~g}$ of the microcline powder was suspended in $30 \mathrm{~mL}$ of $1 \mathrm{M}$ sulfuric or nitric acid solution for about $12 \mathrm{~h}$. To remove the acid, the suspension was centrifuged at $17000 \mathrm{rpm}$ for $10 \mathrm{~min}$ to settle the particles. The supernatant was removed from the sample, its $\mathrm{pH}$ level determined, and the sample diluted with Milli-Q water. This step was repeated several times until the $\mathrm{pH}$ of the supernatant reached the $\mathrm{pH}$ level of deionized water $(\mathrm{pH} \sim 5)$. The pollen washing water was made from two birch pollen samples belonging to the species Betula pendula. One birch pollen sample originated from the Czech Republic (Pharmallerga ${ }^{\circledR}$, referred to as birchS) and the other one from Sweden (Allergon $\mathrm{AB}^{\circledR}{ }^{\circledR}$, referred to as birchN). The sample preparation of the pollen washing water followed the procedure described in Pummer et al. (2012). An amount of $1 \mathrm{~g}$ of the pollen was suspended in $20 \mathrm{~mL}$ of Milli-Q water. After one night (about $12 \mathrm{~h}$ ) in the refrigerator, the pollen grains were removed from the suspension by gravitational filtering (round filter, Schleicher and Schüll Selecta 595, pore size 4-7 $\mu \mathrm{m}$ ).

\subsection{Instrumental setup, particle generation, and size selection}

A schematic of the instrumental setup is shown in Fig. 1. All samples were aerosolized from suspension using a homebuilt atomizer (design similar to TSI, model 3076). Droplets of the suspension were passed through a diffusion dryer, creating particles from the residuals of the droplets, which were size-selected in a differential mobility analyzer (DMA, type Vienna medium; Knutson and Whitby, 1975). For insoluble materials such as kaolinite or feldspar, such a particle could consist of an agglomerate of smaller primary particles. However, the number concentration of primary particles in the dry sample strongly decreases with size for the mineral dust samples and the size range used in this study, which makes the presence of dust agglomerates unlikely. For suspension of birch washing waters containing small macromolecules, an agglomerate of molecules is produced, which is referred to as a (single) aerosol particle after size selection in this work. To remove larger multiple-charged particles, a cyclone $\left(D_{50}=500 \mathrm{~nm}\right)$ was operated at $4 \mathrm{~L} \mathrm{~min}^{-1}$ downstream of 


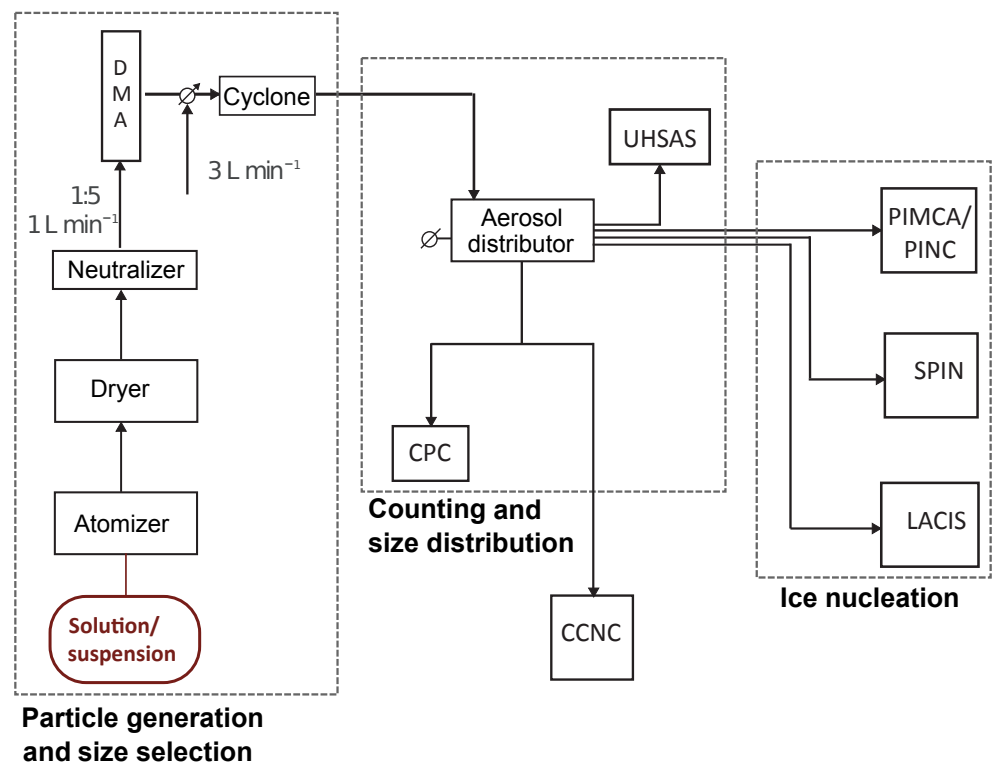

Figure 1. Schematic of the intercomparison setup during LINC. Components include a differential mobility analyzer (DMA), condensation particle counter (CPC), cloud condensation nuclei counter (CCNC), ultra-high-sensitivity aerosol spectrometer (UHSAS), the Leipzig Aerosol Cloud Interaction Simulator (LACIS), the Portable Immersion Mode Cooling chAmber (PIMCA), the Portable Ice Nucleation Chamber (PINC), and the Spectrometer for Ice Nuclei (SPIN).

the DMA. As shown in Fig. 1, downstream of the cyclone an aerosol distributor (mixing volume) supplied the aerosol $\left(\mathrm{RH}_{\mathrm{w}}\right.$ below $\left.1 \%\right)$ to all instruments including a condensation particle counter (CPC, TSI, model 3010), a cloud condensation nuclei counter (CCNC, Droplet Measurement Technologies; Roberts and Nenes, 2005), an ultra-high-sensitivity aerosol spectrometer (UHSAS, Droplet Measurement Technologies), SPIN, LACIS, and either PINC or PIMCA-PINC (see Sect. 2.3 for description of ice nucleation chambers).

Individual impactors upstream of the ice counters were not used for any of the experiments to exclude biases from particle losses. UHSAS measurements indicated a substantial reduction in the number of multiple-charged particles by the cyclone but not a complete removal. Table 1 summarizes the selected particle sizes and the fraction of multiplecharged particles based on UHSAS measurements during the ice nucleation experiments. It was observed that the fraction of multiple-charged particles remained constant in time during each experiment for all particle types investigated. Therefore, the measurements of identical samples at different times have been averaged. CCNC measurements were used to derive particle hygroscopicity values. Hygroscopicity values of acid-treated and untreated particles were similar (with the treated sample having a slightly lower cloud condensation nuclei (CCN) activity), indicating that soluble material added during the acid treatment was completely removed by the applied procedure of repeated rinsing of the sample. The specific particle sizes were chosen to allow measurements in the whole range of detectable frozen and/or activated fractions for all instruments and for comparison with literature data. A limiting factor for larger particle sizes was the particle generation system, which did not produce a sufficiently high particle concentration for simultaneous measurements with all instruments; thus, for example, microcline was not tested for sizes larger than $300 \mathrm{~nm}$. Typical particle concentrations during the ice nucleation experiments measured simultaneously with a CPC were $240 \pm 70 \mathrm{~cm}^{-3}$ for the measurements presented and were diluted to $25-40 \mathrm{~cm}^{-3}$ only for measurements with PIMCA-PINC.

\subsection{Description of ice nucleation chambers}

\subsubsection{PINC}

PINC is a portable parallel-plate vertical CFDC with two individually temperature-controlled walls. Prior to an experiment, a thin ice layer is applied to the chamber walls to provide a source of water vapor. A difference in temperature $(\triangle T)$ is set between the walls that generates a parabolic supersaturation profile with a peak saturation close to the center plane. Sample aerosol is introduced with a flow rate of $1 \mathrm{Lmin}^{-1}$ and layered between two particle-free sheath air flows (4.5 $\mathrm{L} \mathrm{min}^{-1}$ on each side) ensuring a narrow, centered sample lamina. After a residence time $\left(t_{\text {res }}\right)$ of $4-5 \mathrm{~s}$ in the ice nucleation section, the aerosol enters the evaporation section of the chamber where both walls are isothermally set to the warm wall temperature. In the subsaturated environment with respect to liquid water, any formed droplets evaporate while ice crystals are maintained at ice-saturated conditions until detection. At the bottom of the chamber, exiting aerosol 
Table 1. Size and fraction of single- (1) or multiple-charged particles (2, 3, and 4) of the resulting aerosol after size selection and the cyclone.

\begin{tabular}{|c|c|c|c|c|c|}
\hline \multirow[t]{2}{*}{ Aerosol type } & & \multicolumn{4}{|l|}{ Charges } \\
\hline & & 1 & 2 & 3 & 4 \\
\hline \multirow[t]{2}{*}{ Microcline (200 nm) } & Stokes size $(\mathrm{nm})$ & 200 & 324 & 439 & 552 \\
\hline & Fraction & 0.593 & 0.307 & 0.086 & 0.014 \\
\hline \multirow{2}{*}{ Microcline (300 nm) } & Stokes size $(\mathrm{nm})$ & 300 & 507 & 706 & \\
\hline & Fraction & 0.815 & 0.182 & 0.003 & \\
\hline \multirow{2}{*}{ Microcline $\mathrm{H}_{2} \mathrm{SO}_{4}(300 \mathrm{~nm})$} & Stokes size (nm) & 300 & 507 & 706 & \\
\hline & Fraction & 0.821 & 0.162 & 0.017 & \\
\hline \multirow{2}{*}{ Microcline $\mathrm{HNO}_{3}(300 \mathrm{~nm})$} & Stokes size $(\mathrm{nm})$ & 300 & 507 & 706 & \\
\hline & Fraction & 0.867 & 0.131 & 0.002 & \\
\hline \multirow[t]{2}{*}{ Kaolinite (500 nm) } & Stokes size $(\mathrm{nm})$ & 500 & 889 & & \\
\hline & Fraction & 0.988 & 0.012 & & \\
\hline \multirow[t]{2}{*}{ BirchS (500 nm) } & Stokes size $(\mathrm{nm})$ & 500 & 889 & & \\
\hline & Fraction & 0.935 & 0.065 & & \\
\hline \multirow[t]{2}{*}{ BirchN (300 nm) } & Stokes size $(\mathrm{nm})$ & 300 & 507 & 706 & \\
\hline & Fraction & 0.893 & 0.105 & 0.002 & \\
\hline
\end{tabular}

particles and ice crystals are counted by an optical particle counter (OPC, Lighthouse R5104). Particles larger than a set size threshold are counted as ice crystals. For data analysis in this study an ice crystal size threshold of $2 \mu \mathrm{m}$ (diameter) is used. Ice nucleation below water saturation $\left(\mathrm{RH}_{\mathrm{w}}<100 \%\right)$ is classified as deposition nucleation and above water saturation $\left(\mathrm{RH}_{\mathrm{w}} \geq 100 \%\right)$ as condensation freezing. The accuracy of the temperature sensors is $\pm 0.1 \mathrm{~K}$ and the variation in temperature across the sample lamina is $\pm 0.4 \mathrm{~K}$. This corresponds to an uncertainty in $\mathrm{RH}_{\mathrm{w}}$ of $\pm 2 \%$ (Chou et al., 2011). Experiments consist of a scan in $\mathrm{RH}$ at a prescribed $T$ and are conducted from ice saturation to above water saturation up to an RH at which droplets do not completely evaporate in the evaporation section and therefore cannot be distinguished from ice crystals based on size (droplet breakthrough). Before and after each scan, background concentrations of ice crystals in the chamber are obtained while sampling filtered air. Background counts are linearly interpolated between two filter periods and subtracted from the sample signal. The activated fraction $(\mathrm{AF})$ is calculated as the ratio of ice crystals detected with the OPC to the number of total aerosol particles measured with the CPC. Uncertainty in the AF is $14 \%$, resulting from $10 \%$ uncertainty in each of the OPC and CPC measurements. More details on the design and operation of PINC can be found in Chou et al. (2011).

\subsubsection{PIMCA-PINC}

The PIMCA-PINC setup is the portable version of the laboratory design IMCA-ZINC (Lüönd et al., 2010; Stetzer et al., 2008), allowing for measurements explicitly in the immersion freezing mode. PIMCA is a vertical extension of PINC in which aerosol particles are activated as cloud droplets at $313 \mathrm{~K}$ prior to supercooling the droplets to the desired ice nucleation temperature. $\mathrm{RH}_{\mathrm{w}}$ in PINC is set to water satu- ration conditions to maintain cloud droplets at a radius of $5-7 \mu \mathrm{m}$. Flow rates are set to $0.6 \mathrm{~L} \mathrm{~min}^{-1}$ of sample air with $2.2 \mathrm{~L} \mathrm{~min}^{-1}$ of sheath air on either side of the aerosol lamina. This gives a residence time of $\sim 7 \mathrm{~s}$ at ice nucleation conditions in PINC. Ice crystals and cloud droplets are distinguished via depolarization with the ice optical detector (IODE; Nicolet et al., 2010). Unlike the detection system used in the PINC configuration, IODE only observes a small volume of the sample lamina. The frozen fraction (FF) is derived from the ratio of ice crystals to the total particles detected in this subset of the sample. More details on the specifications of the PIMCA-PINC setup can be found in Kohn et al. (2016). In a typical experiment a temperature scan is performed, starting at homogeneous freezing conditions at $T<233 \mathrm{~K}$. Temperature is then increased until the detected FF is not distinguishable anymore from the experimental background. Each reported data point consists of an average of two to five individual measurements at the same $T$. This adds up to more than 3000 individual (particle) intensity peaks analyzed per data point shown. Error bars in the FF indicate the measurement uncertainty from the classification of ice crystals and cloud droplets and the statistical error using standard error propagation. The temperature uncertainty is $\pm 0.4 \mathrm{~K}$ due to variation across the sample lamina and accuracy in the thermocouples of $\pm 0.1 \mathrm{~K}$.

\subsubsection{SPIN}

The SPIN geometry is equivalent to PINC but with a longer ice nucleation section allowing roughly double the residence time. It is the first commercially available ice nucleation chamber (Droplet Measurement Technologies, Inc.) and was recently described by Garimella et al. (2016). Particle residence time in the ice nucleation section is 9-12 s depending on the $T$ and $\mathrm{RH}$ set points of the experiment. Addi- 
tionally, experimental temperatures as low as $228 \mathrm{~K}$ can be reached and the temperature and supersaturation conditions in the evaporation section can be controlled independently from the ice nucleation section. Similar to PINC, ice crystals are discriminated from nonactivated aerosol particles by a size threshold. For this study a threshold size of $2.5 \mu \mathrm{m}$ is used. This threshold size is somewhat larger compared to PINC and chosen to clearly distinguish ice crystals from background counts. For SPIN, the chamber background is determined at the beginning of each $\mathrm{RH}$ scan (relative humidity with respect to ice $\left(\mathrm{RH}_{\mathrm{i}}\right)$ below $103 \%$ ) while sampling aerosol results in a few aerosol counts in the ice channel. This signal is subtracted from the ice counts detected during the experiment. The AF is obtained in the same way as for PINC. Uncertainty in the AF is $14 \%$ due to a $10 \%$ uncertainty in both the SPIN OPC and the CPC. Temperature uncertainties give the highest and lowest deviations from the average lamina temperature to the calculated temperature between 15 opposite pairs of temperature measurements along the walls of SPIN. Experimental uncertainties are typically within $\pm 1 \mathrm{~K}$ for temperature and $\pm 5 \%$ for supersaturation as reported for homogeneous freezing experiments by Garimella et al. (2016).

\subsubsection{LACIS}

LACIS is a laminar flow tube in which, in contrast to icecoated CFDCs, humidified sheath air is the source of water vapor and the ice-covered tube walls are water vapor sinks. LACIS consists of seven $1 \mathrm{~m}$ long tube sections with an internal diameter of $15 \mathrm{~mm}$, with each tube section separately temperature-controlled by a thermostat. The aerosol surrounded by humidified particle-free sheath air enters LACIS in an isokinetic fashion. This leads to the formation of a particle beam with a diameter of roughly $2 \mathrm{~mm}$ at the center of the flow tube. All particles moving along the center line of the laminar flow tube experience the same humidity and temperature conditions, which depend on the inlet dew point and temperature as well as the wall temperature of the tube sections. Detailed information about the setup can be found in Hartmann et al. (2011). In this study LACIS was operated in the immersion mode. Aerosol particles are activated as droplets, which may subsequently freeze upon further cooling while passing through the tube. At the LACIS outlet the ratio of frozen droplets to the total droplet number is determined after a residence time of $1.6 \mathrm{~s}$ at the coldest adjusted temperature. The experimental FF is derived from measurements with the Thermo-stabilized Optical Particle Spectrometer for the detection of ice (TOPS-Ice; Clauss et al., 2013). TOPS-Ice is installed underneath LACIS and it evaluates a change in depolarization in order to distinguish between frozen and unfrozen droplets. For each data point, typically 2000 droplets are examined. The measurement uncertainty in the FF is based on the counting statistics of TOPS-Ice and the Poisson error is given as twice the standard deviation. The temperature error is $\pm 0.3 \mathrm{~K}$.

\section{Results and discussion}

\subsection{Results of immersion freezing measurements}

A total of seven aerosol samples were investigated for immersion freezing during LINC. Figure 2 a summarizes sizesegregated measurements conducted with PIMCA-PINC and LACIS for mineral dusts (top) and pollen washing waters (bottom). For comparison, fit lines to LACIS data from literature derived with the soccer ball model (SBM) are used. The SBM fit lines shown in Fig. 2b, c account for the presence of multiple-charged particles as determined for this study (Table 1) and assume external mixtures for particles of different sizes (i.e., being differently charged). The fit lines also account for the instrumental residence times in PIMCA-PINC $\left(t_{\text {res }} \sim 7 \mathrm{~s}\right)$ and LACIS $\left(t_{\text {res }} \sim 1.6 \mathrm{~s}\right)$. Parameters used for the SBM calculations are taken from Niedermeier et al. (2015), Augustin et al. (2013), Augustin-Bauditz et al. (2016), and Hartmann et al. (2016) (see Appendix A and Table A1 for more details).

For 200 and $300 \mathrm{~nm}$ microcline particles (Fig. 2, teal and orange), a good agreement between the two instruments is observed. The temperature at which half the cloud droplets freeze $\left(T_{50}\right)$ is observed to be $244-244.5 \mathrm{~K}$ for PIMCA-PINC and 244-245.5 K for LACIS. The increase in the FF with decreasing $T$ is reproduced well by the model calculations for PIMCA-PINC (Fig. 2b), but for $T<240 \mathrm{~K}$ the model results underestimate the measurements, which do not show a pronounced plateau as modeled by the SBM but rather only a leveling-off in the slope of the FF curve, i.e., the FF is still increasing slightly with decreasing $T$. A plateau of this kind was also not observed for experiments on other untreated mineral dusts in previous studies using similar instrumentation (e.g., Lüönd et al., 2010; Welti et al., 2012; Kohn et al., 2016). Niedermeier et al. (2015) explain the appearance of a plateau with the assumption that not all particles immersed in a droplet feature an ice-nucleating site. As the ice activity of particles scales with the surface area and, hence, with particle size, the height of this plateau scales with particle size, too, and vanishes for sufficiently large particles. For LACIS the SBM curves underpredict the FF and predict a $T_{50}$ of $1-2 \mathrm{~K}$ lower than the measurement (Fig. 2c). However, the majority of the results are within measurement uncertainty and the plateau is more apparent in the LACIS data. In a recent study by Peckhaus et al. (2016), the SBM was successfully used to reproduce other ice nucleation data from a cold-stage experiment. In principle, a contact angle distribution describes the ice nucleation ability of a material and is then combined with classical nucleation theory in the SBM. Thus, the SBM is not believed to be instrument-specific. It is currently unclear why there is a plateau in the LACIS data that only shows 

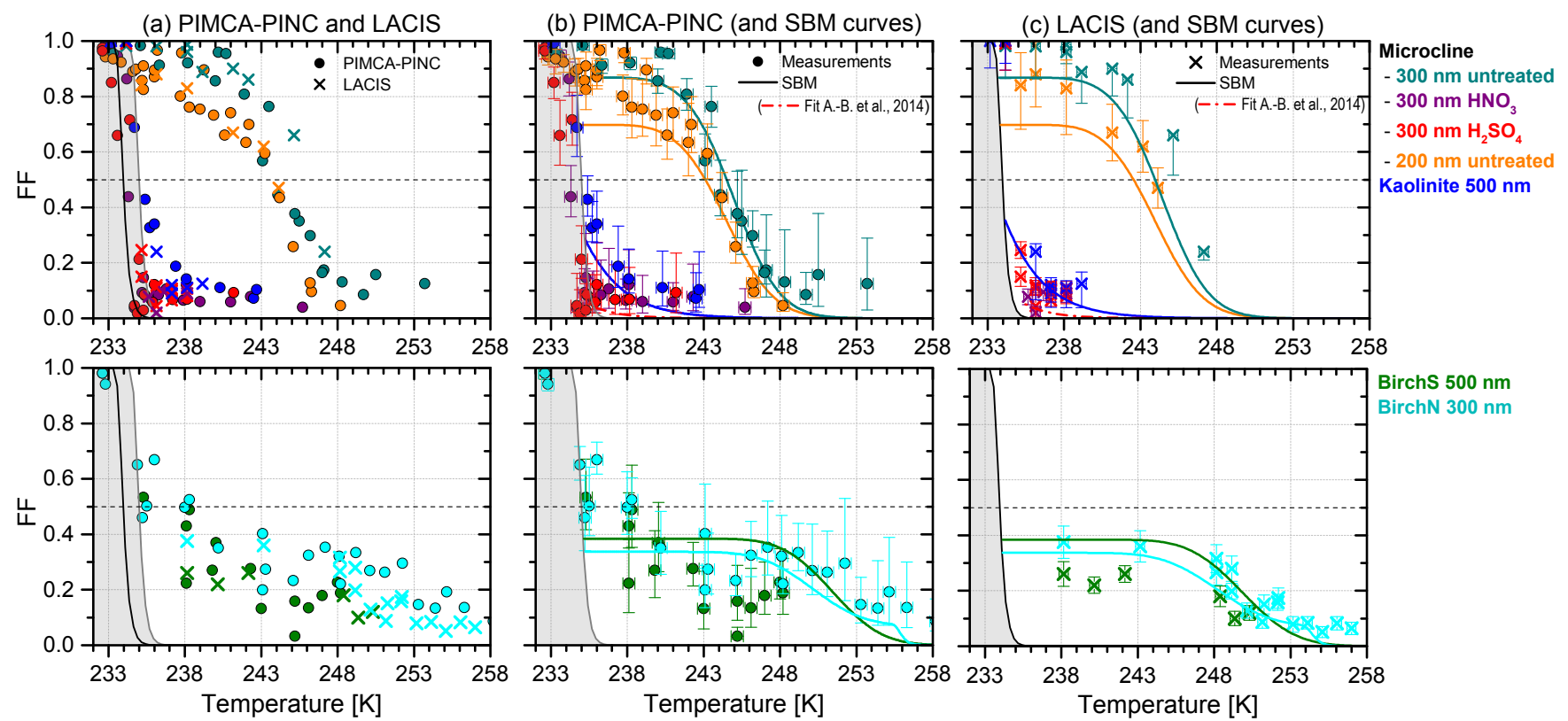

Figure 2. Summary of immersion-mode experiments. (a) Results are shown for untreated and either nitric- or sulfuric-acid-treated mineral dusts (upper panel) and for birch pollen washing waters of two sources (birchS and birchN, lower panel) for PIMCA-PINC and LACIS. The grey and black curves represent homogeneous freezing for PIMCA-PINC (Kohn et al., 2016) and LACIS, respectively, which differ due to differences in droplet size and residence time. $T_{50}$ at which half of the droplets have frozen is indicated by the horizontal dashed black line. Columns (b) and (c): curves (except red) show results of the SBM using fit parameters from literature (see text for details) for comparison to data obtained with PIMCA-PINC (b) and LACIS (c) in this study. The red curve is taken from Augustin-Bauditz et al. (2014) representing a fit line to measurements of acid-coated mineral dust. Error bars show the uncertainty in ice detection and the uncertainty in $T$ in each instrument.

up as a leveling-off of the steep FF slope in the PIMCAPINC results. Also, it should be mentioned that the SBM parameterization used (Niedermeier et al., 2015) is obtained for dry-dispersed particles, while particles examined in this study were dispersed from suspensions. A lowering of the ice activity of feldspars when they were suspended and kept in water for some months prior to ice nucleation measurements is possible. Such effect has been observed in previous immersion freezing studies (Peckhaus et al., 2016; Harrison et al., 2016) and a decrease in $T_{50}$ of $2 \mathrm{~K}$ for the microcline sample used in our study was found by Peckhaus et al. (2016). This could hint towards the lower ice activity in the current study being an effect of the dispersion method. However, it should be added that the suspensions used in this study were at maximum 2 weeks old at the time of measurement. Here, both the measured and modeled data are those for the aerosol, including multiple-charged, i.e., larger particles, which allows direct comparison between our measurements and the SBM model. For completeness, the corrected FFs accounting for multiple-charged particles $\left(\mathrm{FF}_{\text {corr }}\right)$ are given in Appendix $\mathrm{B}$ (Fig. B1), and it can be seen that due to the comparably low fractions of multiple-charged particles, differences between uncorrected and corrected values are not large. However, whenever comparing the FF to literature data, a possible effect of multiple charges has to be kept in mind.
When microcline samples were treated with either sulfuric or nitric acid (Fig. 2, purple and red), the resulting FF was significantly lower and heterogeneous freezing was not quantifiable with PIMCA-PINC due to measurement uncertainties for $T>235 \mathrm{~K}$. In a previous study, Augustin-Bauditz et al. (2014) found a significant decrease in the ice nucleation ability of the same particle type in the immersion mode when coated with sulfuric acid, but without removing the acid prior to the ice nucleation experiment. A fit curve to their data of sulfuric-acid-coated mineral dusts is presented in Fig. 2b, c as a red curve. A similar processing ("weathering") of feldspars with acids has been indicated to form clay minerals in some previous studies (e.g., Zhu et al., 2006). It is noteworthy that acid-treated microcline has a slightly lower freezing curve than kaolinite (Fig. 2, blue). The kaolinite (Fluka) sample in the current study contains about $5 \%$ potassium feldspar (Atkinson et al., 2013), which could explain the higher FF compared to the acid-treated microcline. This study shows that there is a persistent reduction in the ice activity even after removing acid residuals from the microcline surface and it implies altering of the microcline surface properties responsible for its ice nucleation ability. Formation of a clay mineral shell covering the microcline surface could result in a similar ice nucleation ability of kaolinite and acid-treated microcline. Homogeneous freezing is 
observed at lower temperatures for acid-treated microcline samples compared to homogeneous freezing experiments by Kohn et al. (2016, grey area in Fig. 2a, b). A reduction in the hygroscopicity of the aerosol particles due to the acid treatment and washing (see Sect. 2.2) could have led to a delayed droplet activation in PIMCA, leading to smaller droplets and causing a lower $T$ of homogeneous freezing.

Kaolinite particles of $500 \mathrm{~nm}$ (untreated) were less ice active than untreated microcline particles but similar in activity to the acid-treated particles. Heterogeneous freezing between 235 and $243 \mathrm{~K}$ with PIMCA-PINC and 236-239 K with LACIS is observed, but a $T_{50}$ was only reached at homogeneous freezing conditions. The two immersion-mode instruments compare well within uncertainties in the investigated temperature range and with respect to their instrumentspecific homogeneous freezing conditions (Fig. 2a). Kaolinite from the same supplier has also been used in previous work, e.g., in studies with PIMCA-PINC and IMCA-ZINC (Kohn et al., 2016; Lüönd et al., 2010; Welti et al., 2012) and LACIS (Hartmann et al., 2016). Kohn et al. (2016) reported a $T_{50}$ of $238 \mathrm{~K}$ for $400 \mathrm{~nm}$ particles, which agreed well with IMCA-ZINC experiments by Welti et al. (2012) when taking time dependence into account $\left(T_{50}=238.5 \mathrm{~K}\right.$ also for $400 \mathrm{~nm}$ ). The freezing curve, i.e., $T_{50}$ of $500 \mathrm{~nm}$ kaolinite particles measured with PIMCA-PINC, in this study is about $3 \mathrm{~K}$ lower than for the $400 \mathrm{~nm}$ particles used by Kohn et al. (2016) using the same instrument. Alternatively, this can be viewed as for kaolinite; at a fixed $T$ of $238 \mathrm{~K}$, the FF is $\sim 0.3$ lower for $500 \mathrm{~nm}$ than for $400 \mathrm{~nm}$ particles previously investigated. This is surprising given that the larger-sized particles should be more effective INPs (e.g., Archuleta et al., 2005; Welti et al., 2009). SBM fit lines (Fig. 2b, c) are based on data from Hartmann et al. (2016) investigating the same kaolinite sample; however, the SBM underestimates the FF in the present study by up to $0.1-0.15$ in the FF in PIMCAPINC and up to 0.1 in LACIS throughout the investigated temperature range, although both PIMCA-PINC and LACIS results agree within measurement uncertainty with the fit curves (Fig. 2b, c). The fraction of multiple-charged particles is already considered in the presented SBM fit curves in Fig. 2; thus, this is not the reason for the discrepancy. A reason that may contribute to the discrepancy in ice activity when comparing to literature might be the method of particle generation, such as dispersal from an aqueous solution vs. dry dispersal from a powder. Particles in this work were generated from an aqueous suspension, while Kohn et al. (2016), Welti et al. (2012), Lüönd et al. (2010), and Hartmann et al. (2016) examined dry-dispersed particles. Producing particles from an aqueous suspension may lead to a redistribution of soluble material, affecting the exposure of ice active sites on the particle surface. However, in immersion mode a redistribution of solutes on the surface should not play a significant role since the solute should remobilize in the comparatively large droplets formed prior to ice nucleation. A decrease in the freezing temperature was pre- viously observed for microcline during immersion freezing as mentioned above and also for Arizona test dust in watersubsaturated conditions (Koehler et al., 2010). If at all, only a small difference within experimental uncertainty was found between Hartmann et al. (2016, dry-dispersed particles) and LACIS in this study (wet-dispersed particles) for the kaolinite particles. This can be seen by comparing LACIS kaolinite measurements and respective SBM curves in Fig. 2c. Note that measurements with PIMCA-PINC using the same particles show a significant reduction in the ice activity, with a $T_{50}$ of $\sim 2 \mathrm{~K}$ lower for wet-generated kaolinite (Fluka) particles for measurements conducted at ETH Zurich in succession to LINC (see Appendix C for more details). This indicates that there is a change in the ice activity of kaolinite particles when suspended in water and that multiple-charged particles are not the sole reason for this discrepancy. We suggest that setup-specific discrepancies such as the method of particle generation and the quality of size selection plays a non-negligible role that requires close attention to quantitatively compare INP measurements.

The broadest temperature range (233-258 K) investigated during LINC was for the two birch pollen washing waters (Fig. 2, lower panels; cyan and green). Parallel measurements with LACIS and PIMCA-PINC (Fig. 2a) agree well within their uncertainty. The birch pollen washing waters birchS and birchN are active below $258 \mathrm{~K}$. In comparison to the mineral dusts, the FF shows a weaker temperature dependence and the FF levels off below $\sim 248 \mathrm{~K}$, i.e., a fraction of more than $35 \%$ of the droplets froze homogeneously. In the present study, the birchN sample $(300 \mathrm{~nm})$ shows a higher ice activity than birchS $(500 \mathrm{~nm})$. Comparing SBM curves, the results for the birchN sample compare well to Augustin-Bauditz et al. (2016), who tested the same sample batch (Fig. 2b, c). Using fit parameters for birchS from Augustin et al. (2013), the SBM curve overpredicts the FF measured with both PIMCAPINC and LACIS. The lower ice activity of birchS could arise from storage of the sample at room temperature for more than 3 years between measurements done by Augustin et al. (2013), from which the SBM parameters were taken, and the measurements presented herein. The birchS sample seems to lose ice activity during storage, suggesting that care should be taken when comparing results of ice nucleation of biological samples because some samples could potentially change over time. A loss of ice activity over time has also been previously observed for Pseudomonas syringae (e.g., Polen et al., 2016).

In order to quantify the overall instrumental differences between PIMCA-PINC and LACIS, the FF data are averaged in $1 \mathrm{~K}$ bins and plotted in Fig. 3a. A good agreement is found between the two instruments within the experimental uncertainty for the majority of the data. By using the BlandAltman approach (Bland and Altman, 1999), the difference in the FF between PIMCA-PINC and LACIS is calculated as a function of their obtained mean FF and shows no trend (see Fig. 3b), implying that no instrument-specific offset in the 

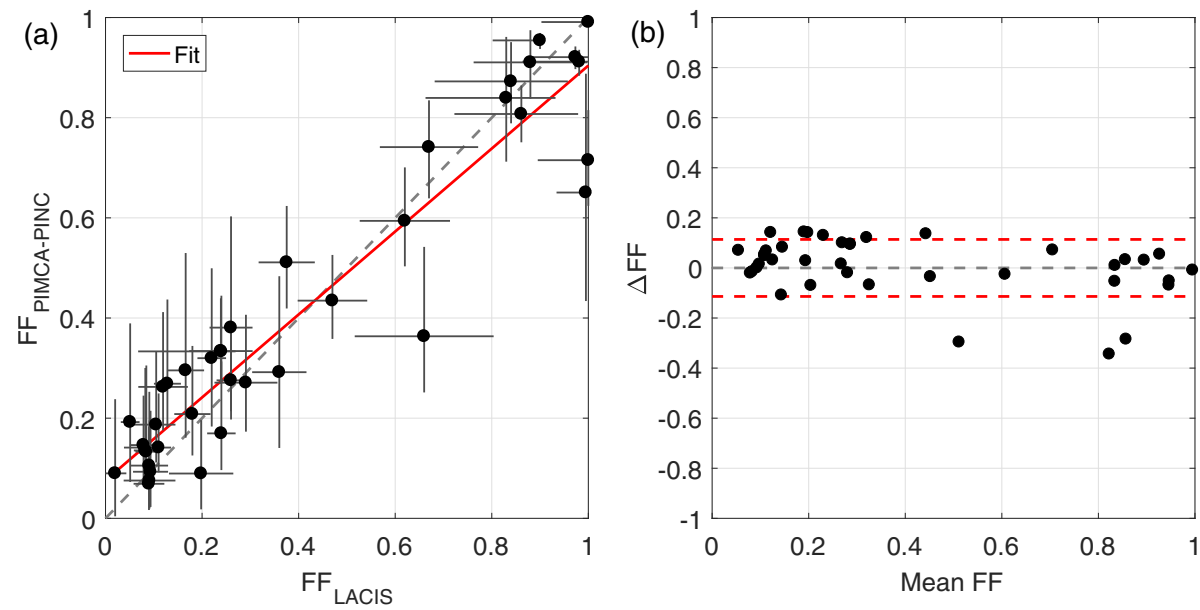

Figure 3. (a) Correlation of frozen fraction for all aerosol types measured between PIMCA-PINC and LACIS. Data are binned in $1 \mathrm{~K}$ intervals for the correlation. The dashed line represents the $1: 1$ line and the red line is a linear fit to all samples. (b) Differences between PIMCA-PINC and LACIS are shown as a function of their mean FF. Dashed red lines show the standard deviation $(1 \sigma)$ range.

FF is observed. This result suggests that discrepancies found previously are not due to the performance of PIMCA-PINC or LACIS in accurately quantifying immersion freezing as results are well within the measurement uncertainties of the instruments when operated in parallel. Instead, it suggests that differences in sample material or treatment of the particles prior to measurements such as the particle generation and the size-selection procedure, as discussed above, could be the cause of previous discrepancies.

\subsection{Results of deposition and condensation mode measurements}

For the first time PINC and SPIN measurements were conducted using the same sample and size-segregated aerosol particles. Experiments between 233 and $253 \mathrm{~K}$ were performed with both instruments by scanning RH from ice saturation up to above water saturation until droplet breakthrough was observed. The tested samples were untreated and nitricacid-treated microcline, kaolinite, and birch pollen washing water (birchN). The ice activity of the individual aerosol types is discussed on the basis of PINC measurements shown in Fig. 4, and the comparison between PINC and SPIN is discussed thereafter.

An active INP in the deposition mode is expected to have a high $\mathrm{AF}$ or activate at lower RH compared to a less active INP. This is observed in the PINC data, which indicates that the most active particles are found at $233 \mathrm{~K}$ with initial onset of ice formation at $\mathrm{RH}_{\mathrm{w}}$ of $82-86 \%$ corresponding to an $\mathrm{RH}_{\mathrm{i}}$ of $121-127 \%$. Among the tested mineral dust samples, the untreated microcline particles $(300 \mathrm{~nm})$ show the highest AF for a given RH (Fig. 4a). The ice formation onset (here defined for convenience of discussion as $\mathrm{AF}=10^{-3}$ ) for untreated microcline at $T=233 \mathrm{~K}$ is observed at $\mathrm{RH}_{\mathrm{w}}=89 \%\left(\mathrm{RH}_{\mathrm{i}}=120 \%\right)$ and the maximum $\mathrm{AF}$ ranges from $6 \times 10^{-1}$ to $3 \times 10^{-3}$ at $236-253 \mathrm{~K}$. Earlier deposition nucleation studies on K-feldspars observed a similar range of the AF (Yakobi-Hancock et al., 2013; Zimmermann et al., 2008). Treatment of microcline with nitric acid (Fig. 4b) resulted in a lower maximum AF of $10^{-2}$ for the temperature range investigated (233-243 K), compared to untreated microcline, which showed an $\mathrm{AF}$ on the order of $10^{-1}$ for the same temperature range. The decrease in ice activity for acid-treated particles was also observed in the immersion freezing experiments as discussed above. Freezing onset conditions do not significantly change with acid treatment below $240 \mathrm{~K}$ (Fig. $4 \mathrm{~b}$ ), but at $243 \mathrm{~K}$ a higher $\mathrm{RH}_{\mathrm{w}}$ is needed to reach $\mathrm{AF}=10^{-3}$. Kulkarni et al. (2014) also reported a reduction in the ice nucleation ability of $200 \mathrm{~nm}$ particles of a K-feldspar sample after coating with sulfuric acid. A general reduction in the ice nucleation ability agrees with the immersion freezing measurements on microcline after treatment with nitric acid presented in this work, but sulfuric acid treatment was not tested with PINC. For a discussion of possible causes of the reduced ice activity after acid treatment, we refer the reader to Sect. 3.1.

The ice nucleation activity of $500 \mathrm{~nm}$ kaolinite particles (Fig. 4c) was tested at four temperatures. Onset freezing conditions $\left(\mathrm{AF}=10^{-3}\right)$ are observed at $\mathrm{RH}_{\mathrm{w}}=90-98 \%$ for the whole measured temperature range. For temperatures 236,240 , and $245 \mathrm{~K}$, a plateauing effect is observed for $\mathrm{RH}_{\mathrm{w}}<100 \%$, indicating the occurrence of a saturation effect of ice nucleation. It is unclear if this would also be observed at $233 \mathrm{~K}$ because the experiment was stopped shortly after reaching water saturation as the limit of the supersaturation attainable by PINC (limited by the cooling power of the walls) was reached. When comparing to previous studies, a 15-20\% higher $\mathrm{RH}_{\mathrm{w}}$ is required in this study to reach an AF of $10^{-3}$ compared to Wex et al. (2014) at $T=239$ $243 \mathrm{~K}$ using $300-700 \mathrm{~nm}$ particles. Also comparing to Welti 

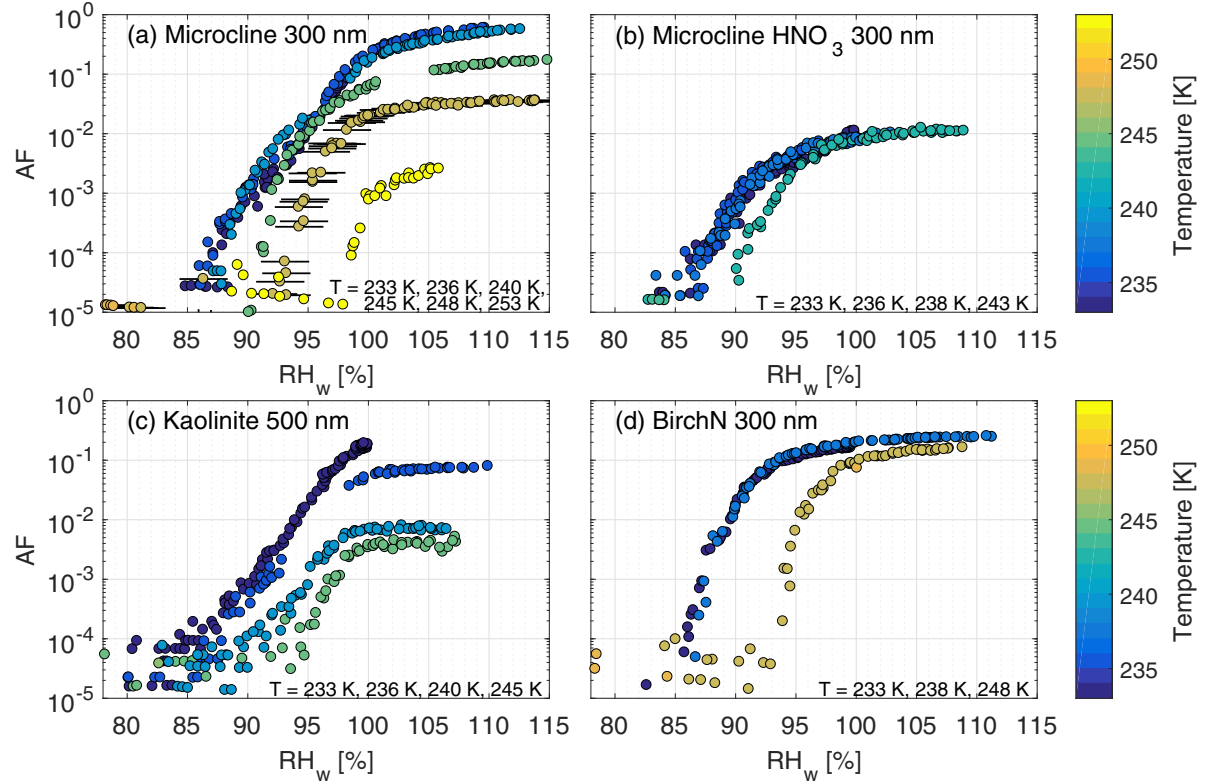

Figure 4. Activated fractions measured with $\mathrm{PINC}$ as a function of $\mathrm{RH}_{\mathrm{W}}$ at measured temperatures for four aerosol types: (a) untreated microcline $(300 \mathrm{~nm})$ and (b) microcline after treatment with $\mathrm{HNO}_{3}(300 \mathrm{~nm})$, (c) kaolinite $(500 \mathrm{~nm})$, and (d) birch pollen washing water (birchN, $300 \mathrm{~nm}$ ). Exemplary measurement uncertainties are given for microcline (a) at $248 \mathrm{~K}$.
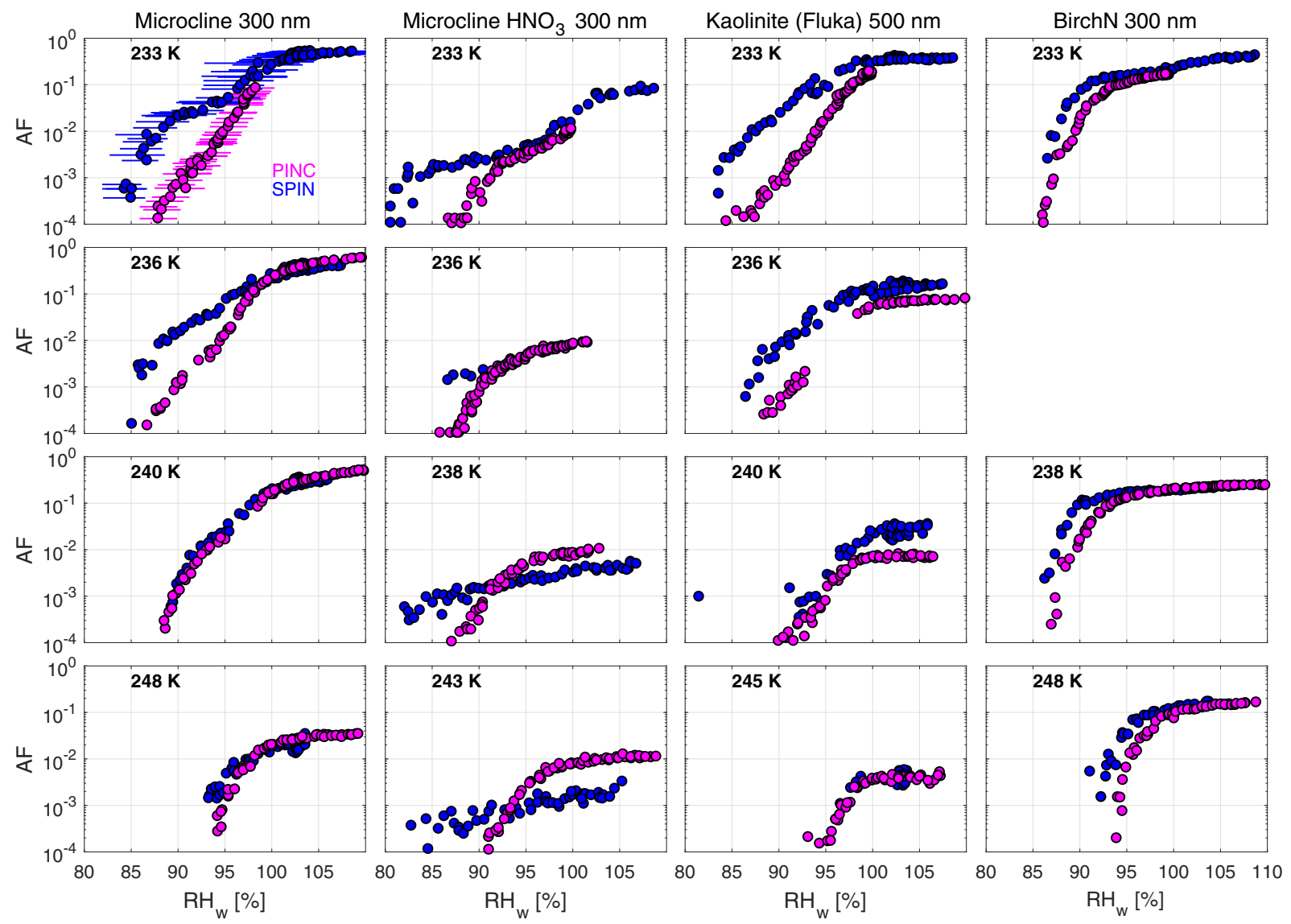

Figure 5. Resulting AF from $\mathrm{RH}_{\mathrm{W}}$ scans measured with PINC (magenta) and SPIN (blue) for four aerosol types. The upper left panel includes an example of measurement uncertainties in the $\mathrm{AF}$ (not visible) and $\mathrm{RH}_{\mathrm{W}}$. 

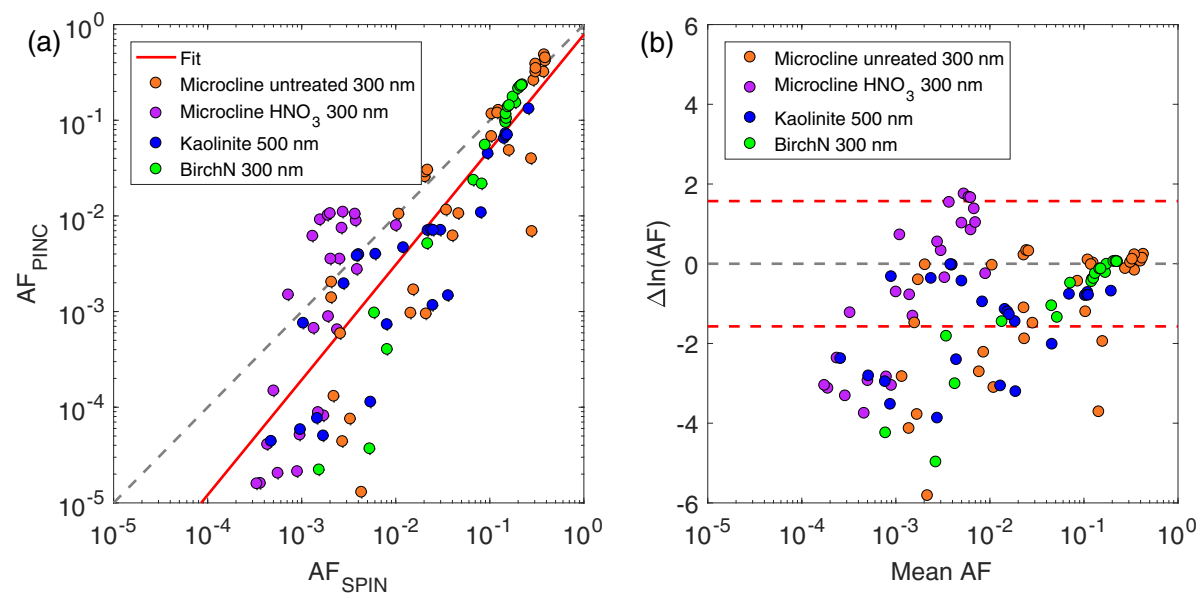

Figure 6. (a) Correlation of the AF measured with PINC and SPIN differentiated for aerosol types. Data are binned in $\pm 2 \%$ in $\mathrm{RH}_{\mathrm{W}}$ to obtain the correlation. (b) Differences in the AF between PINC and SPIN as a function of their mean measured AF. The dashed red lines show the standard deviation $(1 \sigma)$ range.

et al. (2014), the required $\mathrm{RH}_{\mathrm{w}}$ of $94 \%(T=233 \mathrm{~K})$ to reach $\mathrm{AF}=10^{-2}$ in the current work is again $\sim 20 \%$ higher (Welti et al., 2014, $\mathrm{RH}_{\mathrm{w}}=74 \%$ at $T=233 \mathrm{~K}$ using $400 \mathrm{~nm}$ particles). This indicates that kaolinite particles investigated during LINC were less active INPs compared to previous studies. As mentioned before, a difference between previous studies and the present work is that aerosol particles in Welti et al. (2014) and Wex et al. (2014) were dry dispersed. In contrast to immersion freezing, wet-dispersed particles can show a reduced deposition nucleation ability because of soluble material from an aqueous suspension having remobilized to the most hydrophilic locations on the particle surface during drying of the particles before being sampled into an INP counter. In such a case, presumably, the active sites on the particle are blocked and it would be necessary for the $\mathrm{RH}$ to overcome the deliquescence $\mathrm{RH}$ of the soluble material to induce a phase change and a further increase in $\mathrm{RH}$ would be necessary to overcome the solute effect, followed by ice nucleation, resulting in an observed delay in the onset $\mathrm{RH}$ of ice formation. These processes have already been suggested by earlier studies (e.g., Sullivan et al., 2010; Koehler et al., 2010; Alpert et al., 2011; Welti et al., 2014; Wex et al., 2014). Thus, the reduction in activity observed in the deposition nucleation regime suggests, but is not limited to, an effect of the wet dispersion.

Birch pollen washing water (birchN sample, Fig. 4d) shows a steep increase and high maximum value in the AF, suggesting uniformity among the particles responsible for ice nucleation. At $248 \mathrm{~K}$, ice nucleation onset occurs at $94 \%$ $\mathrm{RH}_{\mathrm{w}}$, and at $233 \mathrm{~K}$ the onset $\mathrm{RH}_{\mathrm{w}}$ is $85 \%$. There is only a small temperature dependence of the maximum AF value of the pollen sample, suggesting a threshold temperature required for deposition nucleation on birchN. An additional decrease in temperature results in only a marginal increase in the activated fraction as shown in Fig. 4d.

\section{Comparison between SPIN and PINC}

In Fig. 5 we show SPIN and PINC data for all aerosol types and temperatures investigated with both instruments. Similar dependencies of the $\mathrm{AF}$ on $\mathrm{RH}_{\mathrm{w}}$ and temperature are observed. Quantitatively, SPIN detects higher AFs, with differences more pronounced at lower temperatures and $\mathrm{RH}_{\mathrm{w}}$. For the birchN, the difference at low temperatures is less pronounced than for the mineral dusts, suggesting an aerosolspecific feature leading to instantaneous ice nucleation in the chamber. The birchN particles are the most hygroscopic particles of the samples examined in this work, which was deduced from CCNC measurements in which $300 \mathrm{~nm}$ particles fully activated at a supersaturation of $0.1 \%$ (i.e., the lowest supersaturation sampled), while for all other samples, particle hygroscopicity could be derived, i.e., $50 \%$ active fraction was achieved at a higher supersaturation.

The largest deviation between PINC and SPIN is observed for measurements on nitric-acid-treated microcline, which showed a lower AF measured with SPIN compared to PINC at $T$ values of 238 and $243 \mathrm{~K}$. Note that measurements on nitric-acid-treated microcline were performed on two different batches of nitric-acid-treated samples, i.e., PINC and SPIN did not measure in parallel for this aerosol type for which a discrepancy was not expected. It is possible that the observed difference between SPIN and PINC data is based on the ice active material in the PINC batch, which may not have been as thoroughly deactivated during acid treatment compared to the batch measured with SPIN.

Grouping the data in $\pm 2 \% \mathrm{RH}_{\mathrm{w}}$ and $1 \mathrm{~K}$ temperature bins, AFs measured with PINC and SPIN can be compared (Fig. 6). For the lowest AFs close to the detection limits of SPIN and PINC, scattering is larger as can be seen by the differences between SPIN and PINC as a function of the mean AF (Fig. 6b). The deviation from the $1: 1$ line can be at- 


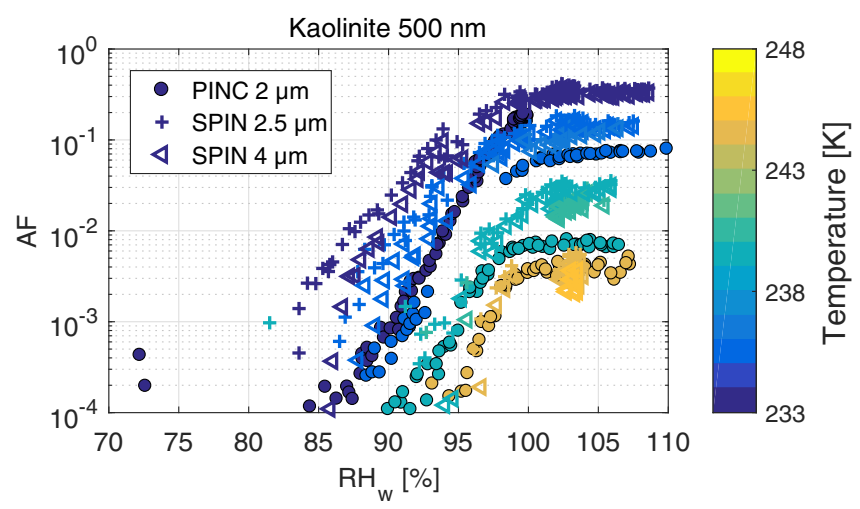

Figure 7. PINC and SPIN RH scans for size-selected kaolinite particles. PINC data are analyzed with an ice crystal size threshold of $2 \mu \mathrm{m}$. SPIN data are presented with the used ice threshold size of $2.5 \mu \mathrm{m}$ and a larger one of $4 \mu \mathrm{m}$.

tributed to $T$ and RH uncertainties and different data analysis procedures, e.g., ice crystal threshold size and instrument design differences such as residence time. These differences are discussed in the following section.

As described in Sect. 2.3.1 and 2.3.3, chamber backgrounds are treated differently for the ice nucleation counters. For PINC, the background is found to increase during the RH scan and a typical background concentration of particle-free air between the start and end of an $\mathrm{RH}$ scan was $3.0 \mathrm{~L}^{-1}$, obtained with a typical sample ice concentration of $6130 \mathrm{~L}^{-1}$ on average, for example, for an experiment on kaolinite at $248 \mathrm{~K}$. Typically the ice crystal concentrations in the experiment that reached $\mathrm{AF} \geq 10^{-3}$ were sufficiently large that the background counts only played a minor role. The relative contribution of the background is higher at a low $\mathrm{AF}$ and $\mathrm{RH}$. It is reasonable to assume that the background counts in SPIN also increase with increases in $\Delta T$ (and RH) as is the case in PINC. However, the lack of a high RH background measurement can yield a lower average background correction as a function of experimental time, resulting in higher ice crystal counts for SPIN than PINC at the end of a RH scan. Note that background estimates for SPIN are justified by the fact that the contribution of aerosol particles is larger than that of the background counts arising from an increase in RH and $\Delta T$. Even though background counts were estimated differently in the two experiments, the resulting change in the AF with or without background correction (see Appendix D for an example on PINC data) neither explains the discrepancies in the $\mathrm{AF}$ at high $\mathrm{RH}_{\mathrm{w}}$ nor the difference in onset conditions. The evaluation of the background could, however, still contribute to differences in the observed AF at low $\mathrm{RH}_{\mathrm{w}}$ as shown by the yellow circles and crosses in Fig. D1 (Appendix D).

Another reason for observed differences between SPIN and PINC arises from the fact that ice crystals are identified using an experiment-specific size threshold to distinguish ice crystals from unactivated aerosol particles, which can complicate a direct comparison, especially at low $T$ and $\mathrm{RH}$ at which ice growth is kinetically limited. The comparison between PINC and SPIN was performed with ice crystal size thresholds of 2 and $2.5 \mu \mathrm{m}$, respectively. The size thresholds were chosen such that ice crystals could accurately be counted while preventing unactivated particles from being falsely counted as ice crystals.

To demonstrate the effect of a change in the threshold size, Fig. 7 shows a comparison of the example of RH scans on kaolinite using a $2 \mu \mathrm{m}$ ice crystal threshold for PINC and either a $2.5 \mu \mathrm{m}$ or $4 \mu \mathrm{m}$ size threshold for SPIN. While the maximum AF observed in SPIN did not change significantly with a change in the threshold size from 2.5 to $4 \mu \mathrm{m}$, the freezing onsets $\left(\mathrm{AF}=10^{-3}\right)$ increased by $3-4 \% \mathrm{RH}_{\mathrm{w}}$. Increasing the ice threshold to $4 \mu \mathrm{m}$ in SPIN gives a better agreement with PINC onset conditions, but not in the maximum AF. Thus, changing the threshold size does not overcome the discrepancy in the AF observed with PINC and SPIN for kaolinite, which suggests that other factors such as time dependence of ice nucleation may contribute to the discrepancy for which the difference in the residence time in the chamber between SPIN $\left(t_{\text {res }} \approx 9 \mathrm{~s}\right)$ and PINC $\left(t_{\text {res }} \approx 5 \mathrm{~s}\right)$ plays a role. For aerosols that demonstrate a nucleation time dependence as has been shown with this kaolinite sample (Welti et al., 2012), longer residence time allows more particles to act as INPs and grow to larger ice crystal sizes before detection. In particular at low $T$, at which the growth rates are lower, this could explain a higher AF measured with SPIN compared to PINC. Following Rogers and Yau (1989), the crystal growth by diffusion for spherical ice crystals as a function of temperature was calculated for the typical residence times in PINC and SPIN (Fig. 8). The mass accommodation coefficient was set to 0.3 based on literature data in Rogers and Yau (1989) ( 0.2 for small ice at $T>263 \mathrm{~K})$ and Skrotzki et al. (2013) (0.2-1 for $T=190-235 \mathrm{~K})$. The initial starting particle diameter was set to $500 \mathrm{~nm}$, the same diameter as used for kaolinite experiments. Note that $t_{\text {res }}$ changes by $1-$ $3 \mathrm{~s}$ depending on the experimental temperature and supersaturation. Assuming instantaneous nucleation of ice upon exposure of the aerosol particles to the chamber conditions, the growth calculations show that for a threshold size of $2 \mu \mathrm{m}$ at $233 \mathrm{~K}$, PINC would detect an ice crystal at $\mathrm{RH}_{\mathrm{w}}=78.5 \%$ and SPIN at $\mathrm{RH}_{\mathrm{w}}=74 \%$ (solid black lines and symbols, Fig. 8). The ice threshold size of $2.5 \mu \mathrm{m}$ used for SPIN in this study accounts for the growth time effect (grey lines), which reduced the observed difference in ice onset to $\sim 1 \%$ $\mathrm{RH}_{\mathrm{w}}$ between PINC and SPIN. While this resulting difference is small, note that due to chamber flow dynamics, the particles are exposed to an $\mathrm{RH}$ range across the aerosol sample lamina of $\pm 2 \%$, depending on the nominal $T$ and $\mathrm{RH}$ condition. Therefore, we expect a range of ice crystal sizes because of the range in $\mathrm{RH}$ as has also been reported recently by Garimella et al. (2017). Further, the calculation shown in Fig. 8 assumes spherical ice crystal growth and also that 


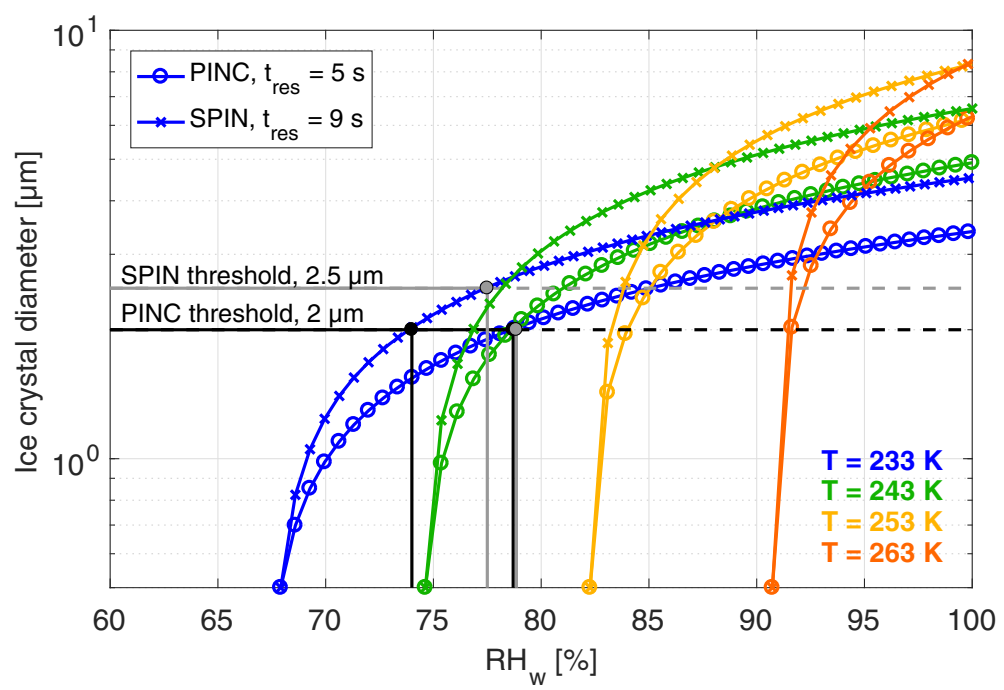

Figure 8. Ice crystal growth calculations for the typical residence times of $5 \mathrm{~s}$ in PINC (circles) and $9 \mathrm{~s}$ in SPIN (crosses), according to Rogers and Yau (1989) using a mass accommodation coefficient of 0.3. Vertical black lines show the discrepancy in $\mathrm{RH}_{\mathrm{W}}$ arising from ice crystals counted with the same ice threshold size of $2 \mu \mathrm{m}$ in both SPIN and PINC. Grey lines indicate the ice threshold size used during LINC resulting in a much smaller discrepancy in onset $\mathrm{RH}_{\mathrm{W}}$. The ice threshold sizes used for PINC and SPIN are indicated by the horizontal dotted lines. Markers on the line plots are spaced by $1 \% \mathrm{RH}_{\mathrm{i}}$.

nucleation is instantaneous and the entire residence time in the nucleation chamber is available for growth. If the latter two were not the case, it would result in a reduction of available time for ice crystal growth, and therefore larger differences would be expected at the position of detection for the two chambers. The efficiency of an INP will therefore influence the proportion of residence time that will be available for growth of the crystal after nucleation has occurred. More efficient INPs would rapidly grow to ice crystals without a large time delay and support the hypothesis of ice growth effects and a weaker time dependence as can be observed for microcline at lower temperatures and birchN (Fig. 5). Instead, less efficient aerosol particles such as kaolinite with a demonstrated time dependence would have a smaller proportion of the residence time available for growth in PINC (residence time of $5 \mathrm{~s}$ ) than in SPIN (residence time of $9 \mathrm{~s}$ ) due to non-instantaneous nucleation upon entering the chamber. This time effect could explain the offset between PINC and SPIN observed at a given RH.

\subsection{Apparent differences between immersion and condensation freezing}

In many field measurements CFDCs have been used for measurements of INP concentration at water-supersaturated conditions (e.g., DeMott et al., 2010, 2016; Tobo et al., 2013; Boose et al., 2016; Lacher et al., 2017) and are sometimes used to represent immersion freezing (e.g., DeMott et al., 2017). As water-supersaturated conditions in CFDCs should result in droplet formation followed by freezing at a constant temperature, CFDCs should simulate condensation freezing (see, e.g., Welti et al., 2014, for a discussion of possible condensation freezing mechanisms). Whether condensation freezing in CFDCs is mechanistically different from immersion freezing is doubtful as both nucleation mechanisms should proceed via the liquid phase, with the requirement of overcoming an activation barrier of ice germ formation from liquid water molecules. How well CFDCs at or above water saturation compare with instruments that explicitly observe immersion freezing has been addressed before (e.g., DeMott et al., 2015; Hiranuma et al., 2015; Garimella et al., 2017).

Here we compare measurements from PIMCA-PINC and LACIS to those from SPIN and PINC (Fig. 9). Possible reasons for observed differences, such as technical artifacts or differences in the ice nucleation modes, are discussed. For simplicity, the FF is used for experiments exclusively performed in the immersion mode. In contrast, for ice nucleation chambers measuring in the condensation mode, which is in this case not explicitly distinguishable from immersion freezing, data are presented as the $\mathrm{AF}$ in the following figures. PIMCA-PINC and PINC cannot be operated at the same time and therefore experiments were repeated on different days. For the three tested aerosol types (microcline, kaolinite, and birchN), a clear offset is found between measurements with PINC and SPIN compared to the immersion freezing experiments in PIMCA-PINC and LACIS (Fig. 9). The maximum $\mathrm{AF}$ in PINC and SPIN did not exceed $\mathrm{AF}=0.6$, even at $\mathrm{RH}_{\mathrm{w}}>105 \%$ at which droplet breakthrough biases the results. An AF of approximately 0.6 was also the highest value reported for SPIN measurements in homogeneous freezing experiments, even well above water saturation and below $233 \mathrm{~K}$ in Garimella et al. (2016). Chamber characterization 


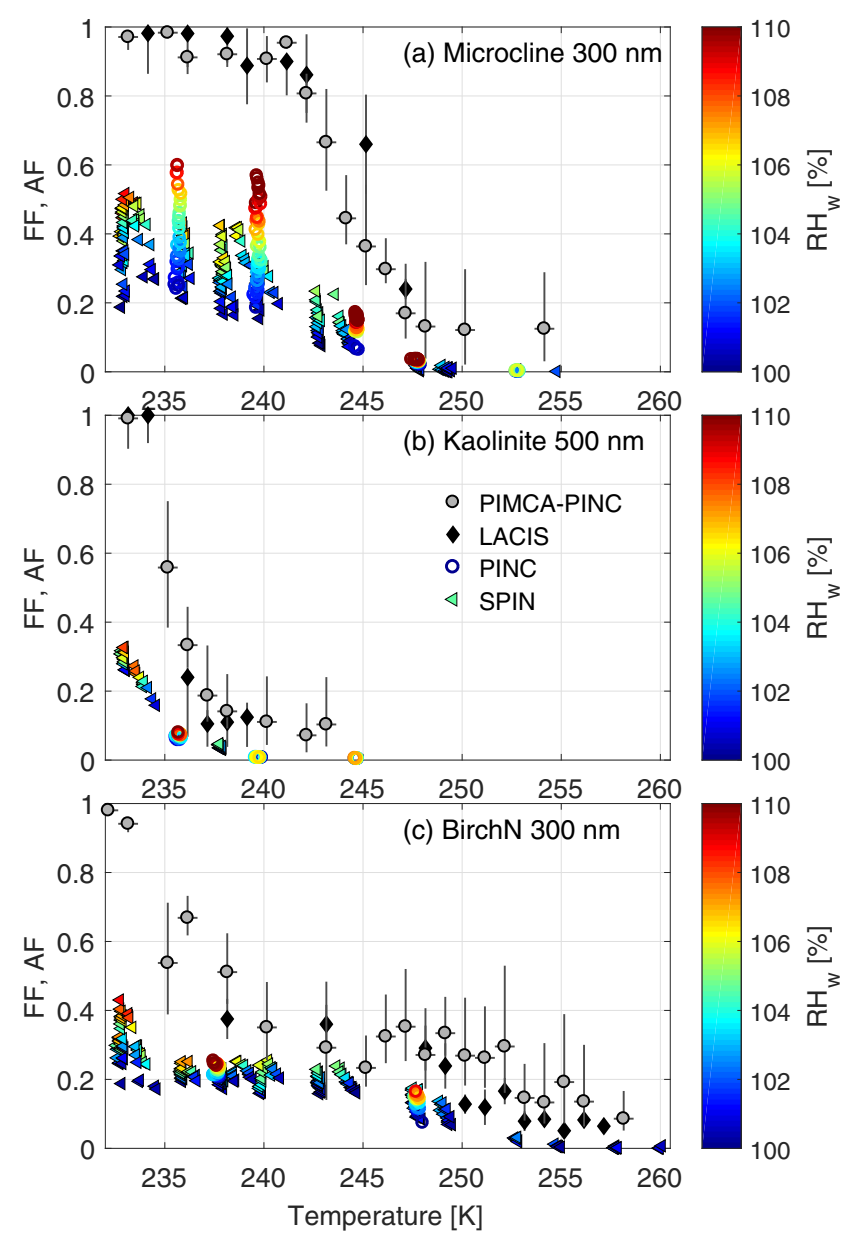

Figure 9. Comparison of all instruments. PIMCA-PINC and LACIS experiments were performed with droplet activation prior to exposure to freezing conditions. Results from immersion freezing experiments are reported as the FF. PINC and SPIN measured the activated fraction $(\mathrm{AF})$ at ice nucleation conditions above water saturation and $\mathrm{RH}_{\mathrm{W}}$ up to droplet breakthrough, which is the limitation for the scan range. $\mathrm{RH}_{\mathrm{W}}$ is indicated by the color bar. The uncertainty in the AF for PINC and SPIN is $14 \%$.

experiments with PINC revealed particle losses below $5 \%$ (Boose et al., 2016); thus, these losses do not explain the observed difference between the CFDC (PINC) and immersion freezing (PIMCA-PINC, LACIS).

In Fig. 10 a scatter plot for the FF of PIMCA-PINC and the $\mathrm{AF}$ of PINC and SPIN obtained at $\mathrm{RH}_{\mathrm{w}}=105 \%$ is shown with lines for ratios of $1: 1,1: 2$, and $1: 3$ between the samples. LACIS data are excluded from the figure for clarity; it is also not necessary for this discussion due to the good agreement found with PIMCA-PINC (Sect. 3.1). For microcline, FFs measured with PIMCA-PINC are a factor of 2-3 higher below $243 \mathrm{~K}$ and more than a factor of 3 higher at higher temperatures. A similar behavior is observed for kaolinite, with factors of 3 or larger required to achieve agreement with immersion freezing. A factor of 3 difference between isothermal CFDC measurements and immersion freezing experiments has previously been reported by DeMott et al. (2015), comparing experiments on mineral dust between CSU-CFDC and the AIDA cloud chamber. In the present study, an offset between the FF and AF is observed for all samples. In particular for the low $T$ measurements the offset is not within measurement uncertainties. It is also noteworthy that the factor is found to change across the different experimental temperatures and aerosol types tested. As an example, for the birchN sample, the factor changed from less than 2 for $T>243 \mathrm{~K}$ up to even larger than 3 for $T \leqslant 235 \mathrm{~K}$.

The disagreement in ice activity observed with the two CFDCs and the two instruments explicitly measuring immersion freezing provides evidence that CFDCs should not be assumed to give the same results as the existing in situ experiments designed to exclusively measure immersion freezing. The results raise the question of what possible differences can lead to this discrepancy and whether these are of a physical or instrumental nature. If the ice nucleation mechanism is the same in all instruments (i.e., ice forms from liquid at the surface of an immersed particle), the most fundamental difference between condensation and immersion freezing experiments is the additional need to create liquid water during condensation freezing, starting with a dry aerosol particle or the presence of soluble material on the particle surface leading to freezing point depression. Recently, DeMott et al. (2015) showed that aerosol particles can in fact be activated inside the CSU-CFDC to a sufficiently large droplet size to investigate immersion freezing in the CFDC for $\mathrm{RH}_{\mathrm{w}}$ well in excess of $100 \%$. However, at which time in the chamber droplet activation occurs and whether the residence time after droplet activation is sufficient to nucleate ice is unclear. Common ice nucleation counters operate on different residence times and if the time is not sufficient for droplet growth in the instrument prior to freezing, a discrepancy is possible. The time that is spent for nucleation and creating sufficient liquid within the growth section of the CFDC would cause a reduction in the observed condensation freezing, especially for INPs that show a time dependence for immersion freezing, which is the case for the kaolinite sample used here (Welti et al., 2012).

In theory, one could increase $\mathrm{RH}_{\mathrm{w}}$ until all particles are activated and nucleate ice; however, the droplet breakthrough imposes limitations on the maximum attainable $\mathrm{RH}_{\mathrm{w}}$ in a CFDC. The question arises as to why such high $\mathrm{RH}_{\mathrm{w}}$ is required to see activation of these particles to ice crystals. It could be morphological or compositional heterogeneity even within a size-segregated sample, implying that only a subset of particles are ice nucleation active. An increase in $\Delta T$ to increase $\mathrm{RH}_{\mathrm{w}}$ causes turbulence in the chamber and changes the flow dynamics in a CFDC at high $\mathrm{RH}_{\mathrm{w}}$ (Rogers, 1988; DeMott et al., 2015), especially for larger temperature gradients of about $10-15 \mathrm{~K}$, causing deviations from ideal flow conditions. Recently, Garimella et al. (2017) have provided 


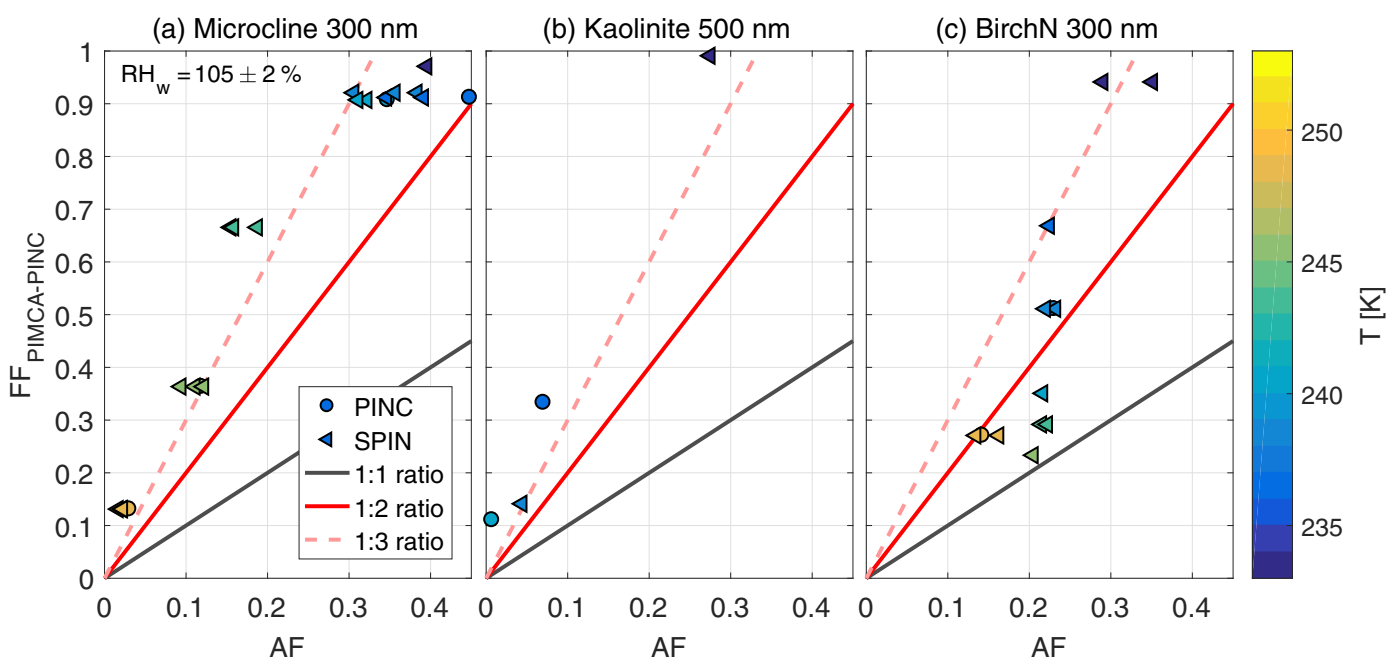

Figure 10. Scatter plot of the FF (immersion freezing) and AF (condensation freezing) showing discrepancies between the instruments. Lines show the $1: 1,1: 2$, and $1: 3$ ratios (black, red, and pink, respectively) for three different aerosol types. PINC and SPIN data are binned by an $\mathrm{RH}_{\mathrm{W}}$ of $\pm 2 \%$.

further empirical evidence that aerosol particles may escape the lamina of CFDC-type instruments resulting in particles being exposed to much lower $\mathrm{RH}_{\mathrm{w}}$ than predicted by ideal behavior of CFDCs, and a resulting variable correction factor of 2.6-9.5 was obtained from their pulse tests. Particles escaping the lamina would require CFDCs to be operated at much higher $\mathrm{RH}_{\mathrm{w}}$ in order to activate all particles to water droplets to truly observe immersion freezing. Aerosol particles that escape the sample lamina cannot be expected to be processed at the set $T$ and RH conditions (mean of the expected lamina), thus potentially leading to an underestimate of counted ice crystals. This underestimate may be more pronounced for higher RH as the increase in turbulence may favor nonideal conditions, further supporting the differences observed between the FF and AF in the work presented here.

Another difference between the CFDCs and the immersion-mode instruments is the different methods of ice crystal detection. While the CFDCs detect the ice crystals as an absolute concentration in the sample air volume via a size threshold (ratio of ice to total particle number entering the chamber), LACIS and PIMCA-PINC observe the ratio of ice to the total number of ice and droplets via depolarization in a subset of the sample, which is a relative fraction. The latter assumes that the sample volume is representative of the total sample air, with the advantage of being less sensitive to particle losses in the chamber and counting efficiency errors arising from two different counting methods (OPC and CPC). Thus, the application of an absolute counting method using depolarization to distinguish the particle phase would combine all advantages in ice detection for future studies.

\section{Summary and outlook}

Experimental results of four online ice nucleation counters were compared using several size-selected aerosol particle types. Two devices designed to observe immersion freezing (PIMCA-PINC and LACIS) and two CFDCs for measuring deposition nucleation and condensation freezing (PINC and SPIN) were used in this study. The investigated aerosol samples were microcline untreated and treated with either sulfuric or nitric acid, kaolinite (Fluka), and two types of birch pollen washing waters. The variety of samples allowed for measurements in the whole temperature (and $\mathrm{RH}$ ) range possible with the chambers.

Treatment of the microcline sample with either sulfuric or nitric acid, followed by washing off the acid, destroyed the ice nucleation ability of the microcline permanently in immersion freezing mode. In addition, the nitric acid treatment led to a significantly reduced AF in deposition nucleation and condensation freezing conditions between 233 and $243 \mathrm{~K}$.

A comparison of parallel measurements with LACIS and PIMCA-PINC, conducted for the first time with these instruments, showed a very good agreement for the investigated aerosol types. No instrument-specific differences for immersion freezing experiments were found in parallel measurements, suggesting that other factors such as the particle size selection and dispersion method may contribute to discrepancies found when comparing results from instruments operated at different times and places. Measurements from the two CFDC instruments PINC and SPIN were compared in the sub- and supersaturated $\mathrm{RH}_{\mathrm{w}}$ regime. Results showed qualitative agreement. However, a direct comparison showed that SPIN detects a higher AF, in particular at low temperatures $(233-236 \mathrm{~K})$ and lower $\mathrm{RH}_{\mathrm{w}}$. Calculations of ice crystal growth revealed that the chamber residence times, in addition 
to the selected ice crystal threshold sizes can largely explain these discrepancies and showed that their effects on reported results from a CFDC cannot be ignored.

Lastly, results from all four instruments were compared to investigate possible differences between condensation $\left(\mathrm{RH}_{\mathrm{w}}=105 \%\right)$ and immersion freezing. Overall, a clear discrepancy on the order of a factor of 3 (or higher) was found between immersion freezing and condensation freezing results, which is similar to the scaling factor of 3 as reported by DeMott et al. (2015) for mineral dust particles. This factor was observed to vary with aerosol type and temperature investigated in this work. When comparing CFDCs with chambers exclusively measuring immersion freezing, the detection methods used to evaluate ice activity should be kept in mind in addition to the $\mathrm{RH}_{\mathrm{w}}$ of the CFDC at which the comparison is done. For instance, CFDC instruments report AFs by measuring absolute ice concentrations from an OPC, which are normalized to total sampled particles from a CPC, while immersion freezing FFs are obtained by normalizing using the ratio of ice crystals to the sum of ice and droplets from the same detector. To determine the extent to which CFDCs are able to measure immersion freezing, further investigation at very high $\mathrm{RH}_{\mathrm{w}}$ allowing for full droplet activation within the residence time of the chamber would be necessary. An assessment of whether the instruments measure the same physical mechanism (i.e., immersion freezing) cannot be made based on the present study. To which extent the observed deviations originate due to the different ice detection methods or residence time for droplet activation requires further investigation and for future studies the use of detectors measuring the absolute number of ice crystals and water droplets by depolarization would be advantageous.
Data availability. The LINC campaign data presented in this publication are available at the following DOI: https://doi.org/10.3929/ethz-b-000186919 (Burkert-Kohn et al., 2017). 


\section{Appendix A: Soccer ball model (SBM)}

The SBM can model temperature-dependent frozen fractions for particles of different materials based on classical nucleation theory and was introduced in detail by Niedermeier et al. (2011). The ice-nucleating sites of the material are represented by a contact angle distribution with an average contact angle, $\mu_{\theta}$, and the standard deviation, $\sigma_{\theta}$, together with an assumed size of the ice active sites, $S_{\text {site. }}$. The abundance of these sites is given by $\lambda$, the average number of sites per particle. The nature of the ice-nucleating sites of the respective material is described by $\mu_{\theta}$ and $\sigma_{\theta}$, i.e., they represent a material property, while $\lambda$ represents the abundance of sites and might differ for different batches of the same material.

Table A1. Parameters used for SBM calculations shown in Fig. 2 with the fractions of multiple-charged particles (Table 1). The average contact angle, $\mu_{\theta}$, and the standard deviation, $\sigma_{\theta}$, of the contact angle distribution and $\lambda$ as a function of the particle diameter $\left(D_{\mathrm{p}}\right)$ and $S_{\text {site }}$ are taken from literature.

\begin{tabular}{lrrrll}
\hline Aerosol type & $S_{\text {site }}\left[\mathrm{m}^{2}\right]$ & $\mu_{\theta}$ [rad] & $\sigma_{\theta}$ [rad] & $\lambda$ & Reference \\
\hline Microcline 200/300 nm & $10^{-14}$ & 1.29 & 0.10 & $2.03 \times 10^{13} \mathrm{~m}^{-2} \times D_{\mathrm{p}}^{2}$ & Niedermeier et al. (2015) \\
Kaolinite 500 nm & $10^{-14}$ & 1.87 & 0.25 & n.a. $\left(n_{\text {site }}=3.14 \times 10^{12} \times D_{\mathrm{p}}^{2}+0.0203\right)$ & Hartmann et al. (2016) \\
BirchN 300 nm & $3.14 \times 10^{-16}$ & 1.016 & 0.080 & (a) $3.30 \times 10^{12} \mathrm{~m}^{-2} \times D_{\mathrm{p}}^{2}$ & Augustin-Bauditz et al. (2016) \\
& $3.14 \times 10^{-16}$ & 0.834 & 0.0005 & (b) $6.65 \times 10^{11} \mathrm{~m}^{-2} \times D_{\mathrm{p}}^{2}$ & Augustin-Bauditz et al. (2016) \\
BirchS 500 nm & $3.14 \times 10^{-16}$ & 1.016 & 0.080 & $1.78 \times 10^{12} \mathrm{~m}^{-2} \times D_{\mathrm{p}}^{2}$ & Augustin et al. (2013)
\end{tabular}

${ }^{a}$ In the case of kaolinite, $n_{\text {site }}$ relates to a former version of the SBM and describes the number of surface sites, which is assumed to be equal for equally sized particles; $\lambda$ is not applicable for this sample. ${ }^{b}$ BirchN parameters are similar to those given in Augustin et al. (2013), with the exception of $\lambda$, i.e., the average number of ice active molecules per particle, which is different due to the use of a different batch of the birchN sample. 
Appendix B: Correcting the frozen fraction for multiple-charged particles

Previously, Hartmann et al. (2016) have introduced the correction for multiple-charged particles in the size distribution of quasi-monodisperse particles to intercompare independent studies on INPs in the immersion mode.

According to Table 1, the FF has been recalculated assuming that all particle sizes feature the identical heterogeneous nucleation rate $\left(J_{\text {het }}\right)$ :

$$
\begin{gathered}
\mathrm{FF}_{\text {calc }}=a_{1} \cdot\left(1-\exp \left(-J_{\text {het }} \cdot A_{1} \cdot t_{\text {res }}\right)\right)+ \\
a_{2} \cdot\left(1-\exp \left(-J_{\text {het }} \cdot A_{2} \cdot t_{\text {res }}\right)\right)+ \\
a_{3} \cdot\left(1-\exp \left(-J_{\text {het }} \cdot A_{3} \cdot t_{\text {res }}\right)\right)+\ldots,
\end{gathered}
$$

with $a_{i}$ being the fraction of particles with $i$ charges and the particle surface area of $A_{i} . J_{\text {het }}$ is chosen to reach the minimum squared error for the difference between the FF and $\mathrm{FF}_{\text {calc }}$. The corrected frozen fraction, $\mathrm{FF}_{\text {corr }}$, is then obtained by

$\mathrm{FF}_{\text {corr }}=1-\exp \left(-J_{\text {het }} \cdot A_{1} \cdot t_{\text {res }}\right)$

as shown in Fig. B1 for measurements with PIMCA-PINC and LACIS.
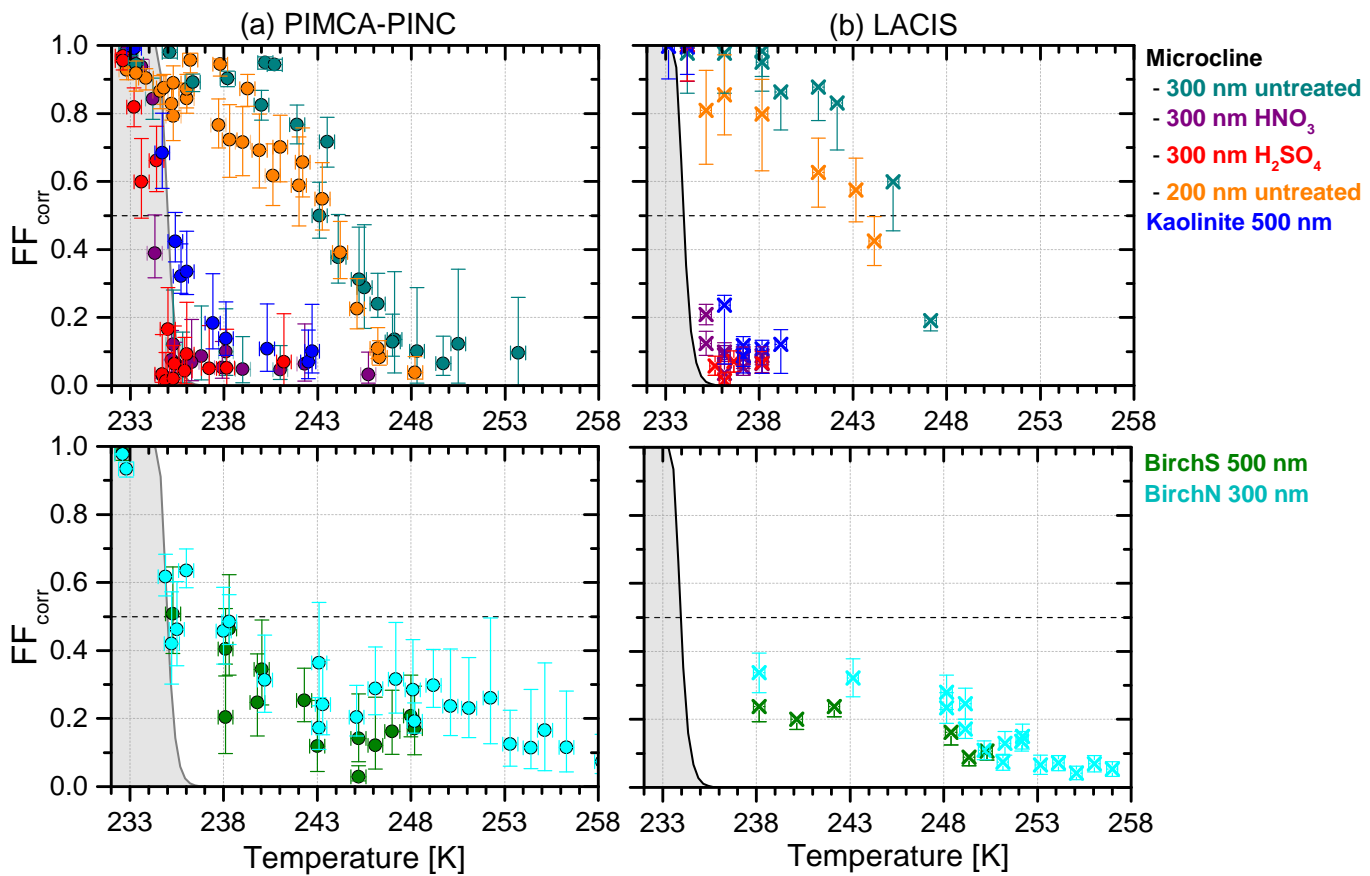

Figure B1. Frozen fraction for results obtained with PIMCA-PINC (a) and LACIS (b) accounting for the fraction of multiple-charged particles in the quasi-monodisperse sample given in Table 1. 


\section{Appendix C: Immersion freezing of kaolinite with PIMCA-PINC using different particle generation methods}

In succession of the LINC study, additional measurements were conducted with PIMCA-PINC using the same kaolinite sample. Results are shown in Fig. C1. Measurements with size-selected particles of $400 \mathrm{~nm}$ were compared when wet and dry generation methods were used. The particles were either dispersed from an aqueous suspension via an atomizer similar to the method in this study or by dry dispersion using a fluidized bed generator (TSI) as described in Kohn et al. (2016). Multiple individual measurements consisting of a temperature scan were conducted. Dry-dispersed FF measurements by Kohn et al. (2016) were reproducible. A difference in the FF based on the particle generation method is clearly observed in this comparison and in particular between temperatures of 235 and $240 \mathrm{~K}$ found to exceed measurement uncertainty.

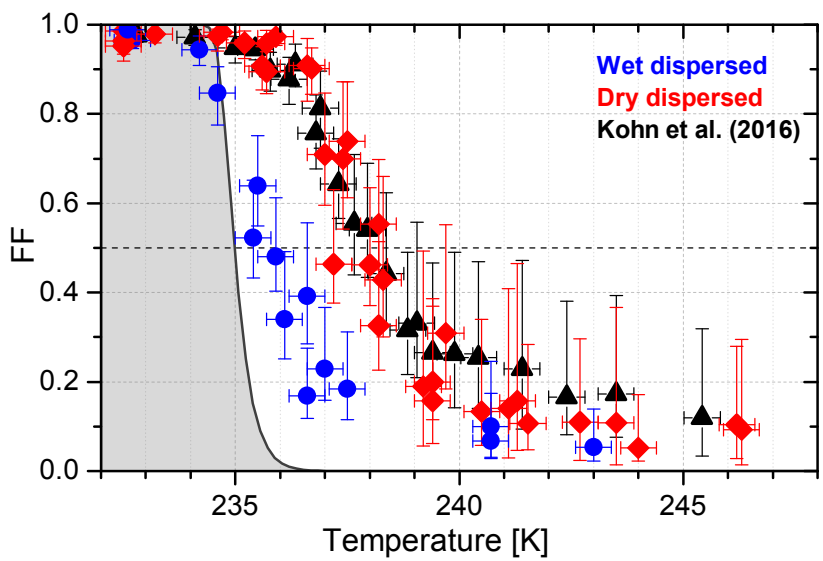

Figure C1. Frozen fraction for measurements of size-selected kaolinite (Fluka) particles $(400 \mathrm{~nm})$ using the PIMCA-PINC instrument after the LINC campaign (blue and red). Data from a previous study by Kohn et al. (2016) are shown for comparison (black; dry dispersed).

\section{Appendix D: Effect of instrument background correction on the activated fraction}

Ice crystal counts in CFDCs are biased by background counts such as frost particles falling off the iced chamber walls that are falsely counted as ice crystals. The background counts are evaluated for PINC at the beginning and at the end of each RH scan. Linear interpolation between the two background measurements is used to determine background counts as a function of RH, which are then subtracted from the sample counts. The background correction for SPIN was conducted in a different manner in the intercomparison study presented. Background counts are determined from the ice crystal counts at the start of $\mathrm{RH}$ scans $\left(\mathrm{RH}_{\mathrm{i}}<103 \%\right)$ at which no ice nucleation is expected. Using sample air allows the inclusion of the concentration of false ice counts due to the measured aerosol population. The change in the AF by accounting for the background in a typical experiment during this study is shown in the example of kaolinite (Fig. D1). It shows that for a high $\mathrm{AF}$ (high $\mathrm{RH}_{\mathrm{w}}$ ) the correction has a minor effect (data points are overlapping). Thus, for measurements presented here the treatment of the background between SPIN and PINC does not affect the main findings. The interpolation through the scan for PINC would in particular affect the values at high $\mathrm{RH}_{\mathrm{w}}$. However, for a low AF closer to the freezing onset, the background correction reduces the AF. Thus, the method of accounting for the background does not explain differences observed between PINC and SPIN. Instead, it supports that for particle concentrations used in this study, accounting for the background counts does not have an influence on the results. It is noteworthy that a stronger effect may be found for experiments with a low observed AF or INP concentration, e.g., when RH scans are conducted in field studies for which the correction of the background has to be carefully considered.

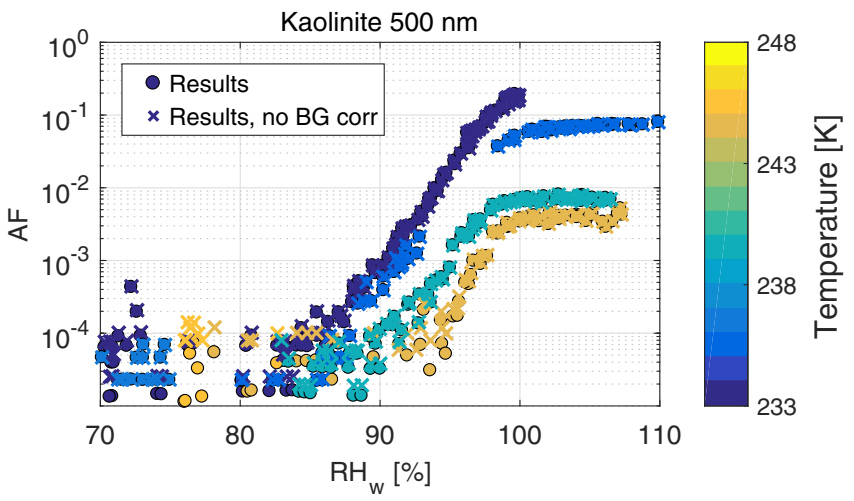

Figure D1. Activated fraction results of PINC, including background correction (circles) as shown in Fig. 7 and raw data without accounting for background counts (crosses). 
Author contributions. MBK prepared the paper with contributions from ZK, HW, SH, AW, SG, and JA. MBK, ZK, AW, and HW interpreted the data with contributions from SH and SG. MBK conducted and analyzed PIMCA-PINC and PINC measurements and prepared all overview figures of the paper. AW and PH ran SPIN measurements and AW analyzed the data. HW oversaw and organized the campaign. SH, SG, and LH operated LACIS and analyzed the data, and all TROPOS participants helped with particle preparation and generation as well as sizing.

Competing interests. The authors declare that they have no conflict of interest.

Special issue statement. This article is part of the special issue "Results from the ice nucleation research unit (INUIT) (ACP/AMT inter-journal SI)". It is not associated with a conference.

This article is part of the special issue "BACCHUS - Impact of Biogenic versus Anthropogenic emissions on Clouds and Climate: towards a Holistic UnderStanding (ACP/AMT/GMD inter-journal SI)". It is not associated with a conference.

Acknowledgements. The work of Monika Burkert-Kohn was funded by grant no. ETH-17 12-1, ETH Zurich. This work is partly funded by the German Research Foundation (DFG), Research Unit FOR 1525 (INUIT), project WE 4722/1-2 and has received funding from the European Union's Seventh Framework Programme (FP7/2007-2013) project BACCHUS under grant agreement no. 603445. We thank Birgit Würz from UFZ for giving support to use the centrifuge, Pharmallerga, for providing pollen samples (birchS) and Hannes Wydler and Thomas Conrath for technical support. The authors are grateful for editing of the paper by Robert O. David and Mikhail Paramonov and for helpful comments on ice growth calculations from Paul J. DeMott.

Edited by: Markus Petters

Reviewed by: two anonymous referees

\section{References}

Alpert, P. A., Aller, J. Y., and Knopf, D. A.: Initiation of the ice phase by marine biogenic surfaces in supersaturated gas and supercooled aqueous phases, Phys. Chem. Chem. Phys., 13, 19882-19894, https://doi.org/10.1039/C1CP21844A, 2011.

Ansmann, A., Tesche, M., Althausen, D., Müller, D., Seifert, P., Freudenthaler, V., Heese, B., Wiegner, M., Pisani, G., Knippertz, P., and Dubovik, O.: Influence of Saharan dust on cloud glaciation in southern Morocco during the Saharan Mineral Dust Experiment, J. Geophys. Res., 113, d04210, https://doi.org/10.1029/2007JD008785, 2008.

Archuleta, C. M., DeMott, P. J., and Kreidenweis, S. M.: Ice nucleation by surrogates for atmospheric mineral dust and mineral dust/sulfate particles at cirrus temperatures, Atmos. Chem. Phys., 5, 2617-2634, https://doi.org/10.5194/acp-5-2617-2005, 2005.
Atkinson, J. D., Murray, B. J., Woodhouse, M. T., Whale, T. F., Baustian, K. J., Carslaw, K. S., Dobbie, S., O'Sullivan, D., and Malkin, T. L.: The importance of feldspar for ice nucleation by mineral dust in mixed-phase clouds, Nature, 498, 355-358, https://doi.org/10.1038/nature12278, 2013.

Augustin, S., Wex, H., Niedermeier, D., Pummer, B., Grothe, H., Hartmann, S., Tomsche, L., Clauss, T., Voigtländer, J., Ignatius, K., and Stratmann, F.: Immersion freezing of birch pollen washing water, Atmos. Chem. Phys., 13, 10989-11003, https://doi.org/10.5194/acp-13-10989-2013, 2013.

Augustin-Bauditz, S., Wex, H., Kanter, S., Ebert, M., Niedermeier, D., Stolz, F., Prager, A., and Stratmann, F.: The immersion mode ice nucleation behavior of mineral dusts: A comparison of different pure and surface modified dusts, Geophys. Res. Lett., 41, 7375-7382, https://doi.org/10.1002/2014GL061317, 2014.

Augustin-Bauditz, S., Wex, H., Denjean, C., Hartmann, S., Schneider, J., Schmidt, S., Ebert, M., and Stratmann, F.: Laboratorygenerated mixtures of mineral dust particles with biological substances: characterization of the particle mixing state and immersion freezing behavior, Atmos. Chem. Phys., 16, 5531-5543, https://doi.org/10.5194/acp-16-5531-2016, 2016.

Bigg, E. K.: Cross Sections of Ice Nucleus Concentrations at Altitude over Long Paths, J. Atmos. Sci., 24, 226-229, https://doi.org/10.1175/15200469(1967)024<0226:CSOINC>2.0.CO;2, 1967.

Bland, J. M. and Altman, D. G.: Measuring agreement in method comparison studies, Stat. Methods Med. Res., 8, 135-160, https://doi.org/10.1177/096228029900800204, 1999.

Boose, Y., Kanji, Z. A., Kohn, M., Sierau, B., Zipori, A., Crawford, I., Lloyd, G., Bukowiecki, N., Herrmann, E., Kupiszewski, P., Steinbacher, M., and Lohmann, U.: Ice nucleating particle measurements at $241 \mathrm{~K}$ during winter months at 3580 m a.s.1. in the Swiss Alps, J. Atmos. Sci., 73, 2203-2228, https://doi.org/10.1175/JAS-D-15-0236.1, 2016.

Boucher, O., Randall, D., Artaxo, P., Bretherton, C., Feingold, G., Forster, P., Kerminen, V.-M., Kondo, Y., Liao, H., Lohmann, U., Rasch, P., Satheesh, S., Sherwood, S., Stevens, B., and Zhang, X.: Clouds and Aerosols, book chap. 7, Cambridge University Press, Cambridge, United Kingdom and New York, NY, USA, https://doi.org/10.1017/CBO9781107415324.016, 571658, 2013.

Burkert-Kohn, M., Wex, H., Welti, A., Hartmann, S., Grawe, S., Hellner, L., Herenz, P., Atkinson, J. D., Stratmann, F., and Kanji, Z. A.: Ice nucleation dataset from the Leipzig ice nucleation chamber comparison (LINC), https://doi.org/10.3929/ethzb-000186919, 2017.

Chou, C., Stetzer, O., Weingartner, E., Jurányi, Z., Kanji, Z. A., and Lohmann, U.: Ice nuclei properties within a Saharan dust event at the Jungfraujoch in the Swiss Alps, Atmos. Chem. Phys., 11, 4725-4738, https://doi.org/10.5194/acp-11-4725-2011, 2011.

Clauss, T., Kiselev, A., Hartmann, S., Augustin, S., Pfeifer, S., Niedermeier, D., Wex, H., and Stratmann, F.: Application of linear polarized light for the discrimination of frozen and liquid droplets in ice nucleation experiments, Atmos. Meas. Tech., 6, 1041-1052, https://doi.org/10.5194/amt-6-1041-2013, 2013.

Conen, F., Henne, S., Morris, C. E., and Alewell, C.: Atmospheric ice nucleators active $\geq-12{ }^{\circ} \mathrm{C}$ can be quantified on $\mathrm{PM}_{10}$ filters, Atmos. Meas. Tech., 5, 321-327, https://doi.org/10.5194/amt-5321-2012, 2012. 
de Boer, G., Morrison, H., Shupe, M. D., and Hildner, R.: Evidence of liquid dependent ice nucleation in high-latitude stratiform clouds from surface remote sensors, Geophys. Res. Lett., 38, 101803, https://doi.org/10.1029/2010GL046016, 2011.

DeMott, P. J., Cziczo, D. J., Prenni, A. J., Murphy, D. M., Kreidenweis, S. M., Thomson, D. S., Borys, R., and Rogers, D. C.: Measurements of the concentration and composition of nuclei for cirrus formation, P. Natl. Acad. Sci. USA, 100, 14655-14660, https://doi.org/10.1073/pnas.2532677100, 2003a.

DeMott, P. J., Sassen, K., Poellot, M. R., Baumgardner, D., Rogers, D. C., Brooks, S. D., Prenni, A. J., and Kreidenweis, S. M.: African dust aerosols as atmospheric ice nuclei, Geophys. Res. Lett., 30, 14, https://doi.org/10.1029/2003GL017410, 2003 b.

DeMott, P. J., Prenni, A. J., Liu, X., Kreidenweis, S. M., Petters, M. D., Twohy, C. H., Richardson, M. S., Eidhammer, T., and Rogers, D. C.: Predicting global atmospheric ice nuclei distributions and their impacts on climate, P. Natl. Acad. Sci. USA, 107, 11217-11222, https://doi.org/10.1073/pnas.0910818107, 2010.

DeMott, P. J., Möhler, O., Stetzer, O., Vali, G., Levin, Z., Petters, M. D., Murakami, M., Leisner, T., Bundke, U., Klein, H., Kanji, Z. A., Cotton, R., Jones, H., Benz, S., Brinkmann, M., Rzesanke, D., Saathoff, H., Nicolet, M., Saito, A., Nillius, B., Bingemer, H., Abbatt, J., Ardon, K., Ganor, E., Georgakopoulos, D. G., and Saunders, C.: Resurgence In Ice Nuclei Measurement Research, B. Am. Meteorol. Soc., 92, 1623-1635, https://doi.org/10.1175/2011BAMS3119.1, 2011.

DeMott, P. J., Prenni, A. J., McMeeking, G. R., Sullivan, R. C., Petters, M. D., Tobo, Y., Niemand, M., Möhler, O., Snider, J. R., Wang, Z., and Kreidenweis, S. M.: Integrating laboratory and field data to quantify the immersion freezing ice nucleation activity of mineral dust particles, Atmos. Chem. Phys., 15, 393-409, https://doi.org/10.5194/acp-15-393-2015, 2015.

DeMott, P. J., Hill, T. C. J., McCluskey, C. S., Prather, K. A., Collins, D. B., Sullivan, R. C., Ruppel, M. J., Mason, R. H., Irish, V. E., Lee, T., Hwang, C. Y., Rhee, T. S., Snider, J. R., McMeeking, G. R., Dhaniyala, S., Lewis, E. R., Wentzell, J. J. B., Abbatt, J., Lee, C., Sultana, C. M., Ault, A. P., Axson, J. L., Diaz Martinez, M., Venero, I., Santos-Figueroa, G., Stokes, M. D., Deane, G. B., Mayol-Bracero, O. L., Grassian, V. H., Bertram, T. H., Bertram, A. K., Moffett, B. F., and Franc, G. D.: Sea spray aerosol as a unique source of ice nucleating particles, P. Natl. Acad. Sci. USA, 113, 5797-5803, https://doi.org/10.1073/pnas.1514034112, 2016.

DeMott, P. J., Hill, T. C. J., Petters, M. D., Bertram, A. K., Tobo, Y., Mason, R. H., Suski, K. J., McCluskey, C. S., Levin, E. J. T., Schill, G. P., Boose, Y., Rauker, A. M., Miller, A. J., Zaragoza, J., Rocci, K., Rothfuss, N. E., Taylor, H. P., Hader, J. D., Chou, C., Huffman, J. A., Pöschl, U., Prenni, A. J., and Kreidenweis, S. M.: Comparative measurements of ambient atmospheric concentrations of ice nucleating particles using multiple immersion freezing methods and a continuous flow diffusion chamber, Atmos. Chem. Phys., 17, 11227-11245, https://doi.org/10.5194/acp-1711227-2017, 2017.

Garcia, E., Hill, T. C. J., Prenni, A. J., DeMott, P. J., Franc, G. D., and Kreidenweis, S. M.: Biogenic ice nuclei in boundary layer air over two U.S. High Plains agricultural regions, J. Geophys. Res., 117, D18209, https://doi.org/10.1029/2012JD018343, 2012.

Garimella, S., Kristensen, T. B., Ignatius, K., Welti, A., Voigtländer, J., Kulkarni, G. R., Sagan, F., Kok, G. L., Dorsey, J., Nich- man, L., Rothenberg, D. A., Rösch, M., Kirchgäßner, A. C. R., Ladkin, R., Wex, H., Wilson, T. W., Ladino, L. A., Abbatt, J. P. D., Stetzer, O., Lohmann, U., Stratmann, F., and Cziczo, D. J.: The SPectrometer for Ice Nuclei (SPIN): an instrument to investigate ice nucleation, Atmos. Meas. Tech., 9, 2781-2795, https://doi.org/10.5194/amt-9-2781-2016, 2016.

Garimella, S., Rothenberg, D. A., Wolf, M. J., David, R. O., Kanji, Z. A., Wang, C., Rösch, M., and Cziczo, D. J.: Uncertainty in counting ice nucleating particles with continuous flow diffusion chambers, Atmos. Chem. Phys., 17, 10855-10864, https://doi.org/10.5194/acp-17-10855-2017, 2017.

Hader, J. D., Wright, T. P., and Petters, M. D.: Contribution of pollen to atmospheric ice nuclei concentrations, Atmos. Chem. Phys., 14, 5433-5449, https://doi.org/10.5194/acp-145433-2014, 2014.

Harrison, A. D., Whale, T. F., Carpenter, M. A., Holden, M. A., Neve, L., O'Sullivan, D., Vergara Temprado, J., and Murray, B. J.: Not all feldspars are equal: a survey of ice nucleating properties across the feldspar group of minerals, Atmos. Chem. Phys., 16, 10927-10940, https://doi.org/10.5194/acp-16-109272016, 2016.

Hartmann, S., Niedermeier, D., Voigtländer, J., Clauss, T., Shaw, R. A., Wex, H., Kiselev, A., and Stratmann, F.: Homogeneous and heterogeneous ice nucleation at LACIS: operating principle and theoretical studies, Atmos. Chem. Phys., 11, 1753-1767, https://doi.org/10.5194/acp-11-1753-2011, 2011.

Hartmann, S., Wex, H., Clauss, T., Augustin-Bauditz, S., Niedermeier, D., Rösch, M., and Stratmann, F.: Immersion Freezing of Kaolinite: Scaling with Particle Surface Area, J. Atmos. Sci., 73 , 263-278, https://doi.org/10.1175/JAS-D-15-0057.1, 2016.

Hiranuma, N., Augustin-Bauditz, S., Bingemer, H., Budke, C., Curtius, J., Danielczok, A., Diehl, K., Dreischmeier, K., Ebert, M., Frank, F., Hoffmann, N., Kandler, K., Kiselev, A., Koop, T., Leisner, T., Möhler, O., Nillius, B., Peckhaus, A., Rose, D., Weinbruch, S., Wex, H., Boose, Y., DeMott, P. J., Hader, J. D., Hill, T. C. J., Kanji, Z. A., Kulkarni, G., Levin, E. J. T., McCluskey, C. S., Murakami, M., Murray, B. J., Niedermeier, D., Petters, M. D., O’Sullivan, D., Saito, A., Schill, G. P., Tajiri, T., Tolbert, M. A., Welti, A., Whale, T. F., Wright, T. P., and Yamashita, K.: A comprehensive laboratory study on the immersion freezing behavior of illite NX particles: a comparison of 17 ice nucleation measurement techniques, Atmos. Chem. Phys., 15, 2489-2518, https://doi.org/10.5194/acp-15-2489-2015, 2015.

Kanji, Z. A., DeMott, P. J., Möhler, O., and Abbatt, J. P. D.: Results from the University of Toronto continuous flow diffusion chamber at ICIS 2007: instrument intercomparison and ice onsets for different aerosol types, Atmos. Chem. Phys., 11, 31-41, https://doi.org/10.5194/acp-11-31-2011, 2011.

Kanji, Z. A., Ladino, L. A., Wex, H., Boose, Y., BurkertKohn, M., Cziczo, D. J., and Krämer, M.: Ice Formation and Evolution in Clouds and Precipitation: Measurement and Modeling Challenges, Chapter 1: Overview of Ice Nucleating Particles, Meteor. Mon., 58, 1.1-1.33, https://doi.org/10.1175/AMSMONOGRAPHS-D-16-0006.1, 2017.

Klein, H., Nickovic, S., Haunold, W., Bundke, U., Nillius, B., Ebert, M., Weinbruch, S., Schuetz, L., Levin, Z., Barrie, L. A., and Bingemer, H.: Saharan dust and ice nuclei 
over Central Europe, Atmos. Chem. Phys., 10, 10211-10221, https://doi.org/10.5194/acp-10-10211-2010, 2010.

Knutson, E. and Whitby, K.: Aerosol classification by electric mobility: apparatus, theory, and applications, J. Aerosol Sci., 6, 443-451, https://doi.org/10.1016/0021-8502(75)90060-9, 1975.

Koehler, K. A., Kreidenweis, S. M., DeMott, P. J., Petters, M. D., Prenni, A. J., and Möhler, O.: Laboratory investigations of the impact of mineral dust aerosol on cold cloud formation, Atmos. Chem. Phys., 10, 11955-11968, https://doi.org/10.5194/acp-1011955-2010, 2010.

Kohn, M., Lohmann, U., Welti, A., and Kanji, Z. A.: Immersion mode ice nucleation measurements with the new Portable Immersion Mode Cooling chAmber (PIMCA), J. Geophys. Res.-Atmos., 121, 4713-4733, https://doi.org/10.1002/2016JD024761, 2016.

Kulkarni, G., Sanders, C., Zhang, K., Liu, X., and Zhao, C.: Ice nucleation of bare and sulfuric acid-coated mineral dust particles and implication for cloud properties, J. Geophys. Res., 119, 9993-10011, https://doi.org/10.1002/2014JD021567, 2014JD021567, 2014.

Lacher, L., Lohmann, U., Boose, Y., Zipori, A., Herrmann, E., Bukowiecki, N., Steinbacher, M., and Kanji, Z. A.: The Horizontal Ice Nucleation Chamber HINC: INP measurements at Conditions Relevant for Mixed-Phase Clouds at the High Altitude Research Station Jungfraujoch, Atmos. Chem. Phys. Discuss., https://doi.org/10.5194/acp-2017-474, in review, 2017.

Lohmann, U. and Feichter, J.: Global indirect aerosol effects: a review, Atmos. Chem. Phys., 5, 715-737, https://doi.org/10.5194/acp-5-715-2005, 2005.

Lüönd, F., Stetzer, O., Welti, A., and Lohmann, U.: Experimental study on the ice nucleation ability of size-selected kaolinite particles in the immersion mode, J. Geophys. Res., 115, D1402, https://doi.org/10.1029/2009JD012959, 2010.

Marcolli, C.: Deposition nucleation viewed as homogeneous or immersion freezing in pores and cavities, Atmos. Chem. Phys., 14, 2071-2104, https://doi.org/10.5194/acp-14-2071-2014, 2014.

Mülmenstädt, J., Sourdeval, O., Delanoë, J., and Quaas, J.: Frequency of occurrence of rain from liquid-, mixed-, and ice-phase clouds derived from A-Train satellite retrievals, Geophys. Res. Lett., 42, 6502-6509, https://doi.org/10.1002/2015GL064604, 2015.

Murray, B. J., O'Sullivan, D., Atkinson, J. D., and Webb, M. E.: Ice nucleation by particles immersed in supercooled cloud droplets, Chem. Soc. Rev., 41, 6519-6554, https://doi.org/10.1039/C2CS35200A, 2012.

Nicolet, M., Stetzer, O., Lüönd, F., Möhler, O., and Lohmann, U.: Single ice crystal measurements during nucleation experiments with the depolarization detector IODE, Atmos. Chem. Phys., 10, 313-325, https://doi.org/10.5194/acp-10-313-2010, 2010.

Niedermeier, D., Shaw, R. A., Hartmann, S., Wex, H., Clauss, T., Voigtländer, J., and Stratmann, F.: Heterogeneous ice nucleation: exploring the transition from stochastic to singular freezing behavior, Atmos. Chem. Phys., 11, 8767-8775, https://doi.org/10.5194/acp-11-8767-2011, 2011.

Niedermeier, D., Augustin-Bauditz, S., Hartmann, S., Wex, H., Ignatius, K., and Stratmann, F.: Can we define an asymptotic value for the ice active surface site density for heterogeneous ice nucleation?, J. Geophys. Res., 120, 5036-5046, https://doi.org/10.1002/2014JD022814, 2014JD022814, 2015.
Peckhaus, A., Kiselev, A., Hiron, T., Ebert, M., and Leisner, T.: A comparative study of K-rich and $\mathrm{Na} / \mathrm{Ca}$-rich feldspar icenucleating particles in a nanoliter droplet freezing assay, Atmos. Chem. Phys., 16, 11477-11496, https://doi.org/10.5194/acp-1611477-2016, 2016.

Phillips, V. T. J., Demott, P. J., Andronache, C., Pratt, K. A., Prather, K. A., Subramanian, R., and Twohy, C.: Improvements to an Empirical Parameterization of Heterogeneous Ice Nucleation and Its Comparison with Observations, J. Atmos. Sci., 70, 378-409, https://doi.org/10.1175/JAS-D-12-080.1, 2013.

Polen, M., Lawlis, E., and Sullivan, R. C.: The unstable ice nucleation properties of Snomax $^{\circledR}$ bacterial particles, J. Geophys. Res.-Atmos., 121, 11666-11678, https://doi.org/10.1002/2016JD025251, 2016.

Pruppacher, H. and Klett, J.: Microphysics of Clouds and Precipitation, Atmospheric and Oceanographic Sciences Library, Kluwer Academic Publishers, 1997.

Pummer, B. G., Bauer, H., Bernardi, J., Bleicher, S., and Grothe, H.: Suspendable macromolecules are responsible for ice nucleation activity of birch and conifer pollen, Atmos. Chem. Phys., 12, 2541-2550, https://doi.org/10.5194/acp-12-2541-2012, 2012.

Roberts, G. C. and Nenes, A.: A Continuous-Flow Streamwise Thermal-Gradient CCN Chamber for Atmospheric Measurements, Aerosol Sci. Tech., 39, 206-221, https://doi.org/10.1080/027868290913988, 2005.

Rogers, D. C.: Development of a continuous flow thermal gradient diffusion chamber for ice nucleation studies, Atmos. Res., 22, 149-181, https://doi.org/10.1016/0169-8095(88)90005-1, 1988.

Rogers, D. C., DeMott, P. J., and Kreidenweis, S. M.: Airborne measurements of tropospheric ice-nucleating aerosol particles in the Arctic spring, J. Geophys. Res., 106, 15053-15063, https://doi.org/10.1029/2000JD900790, 2001a.

Rogers, D. C., DeMott, P. J., Kreidenweis, S. M., and Chen, Y.: A Continuous-Flow Diffusion Chamber for Airborne Measurements of Ice Nuclei, J. Atmos. Ocean. Tech., 18, 725-741, https://doi.org/10.1175/15200426(2001)018<0725:ACFDCF>2.0.CO;2, $2001 \mathrm{~b}$.

Rogers, R. and Yau, M.: A Short Course in Cloud Physics, vol. 113, Elsevier Science, 3rd Edn., 1989.

Skrotzki, J., Connolly, P., Schnaiter, M., Saathoff, H., Möhler, O., Wagner, R., Niemand, M., Ebert, V., and Leisner, T.: The accommodation coefficient of water molecules on ice - cirrus cloud studies at the AIDA simulation chamber, Atmos. Chem. Phys., 13, 4451-4466, https://doi.org/10.5194/acp-134451-2013, 2013.

Stetzer, O., Baschek, B., Lüönd, F., and Lohmann, U.: The Zurich Ice Nucleation Chamber ZINC-A New Instrument to Investigate Atmospheric Ice Formation, Aerosol Sci. Tech., 42, 64-74, https://doi.org/10.1080/02786820701787944, 2008.

Sullivan, R. C., Petters, M. D., DeMott, P. J., Kreidenweis, S. M., Wex, H., Niedermeier, D., Hartmann, S., Clauss, T., Stratmann, F., Reitz, P., Schneider, J., and Sierau, B.: Irreversible loss of ice nucleation active sites in mineral dust particles caused by sulphuric acid condensation, Atmos. Chem. Phys., 10, 1147111487, https://doi.org/10.5194/acp-10-11471-2010, 2010.

Tobo, Y., Prenni, A. J., DeMott, P. J., Huffman, J. A., McCluskey, C. S., Tian, G., Pöhlker, C., Pöschl, U., and Kreidenweis, S. M.: Biological aerosol particles as a key determinant of ice nuclei 
populations in a forest ecosystem, J. Geophys. Res., 118, 1010010110, https://doi.org/10.1002/jgrd.50801, 2013.

Vali, G.: Nucleation terminology, J. Aerosol Sci., 16, 575-576, https://doi.org/10.1016/0021-8502(85)90009-6, 1985.

Vali, G., DeMott, P. J., Möhler, O., and Whale, T. F.: Technical Note: A proposal for ice nucleation terminology, Atmos. Chem. Phys., 15, 10263-10270, https://doi.org/10.5194/acp-15-102632015, 2015.

Welti, A., Lüönd, F., Stetzer, O., and Lohmann, U.: Influence of particle size on the ice nucleating ability of mineral dusts, Atmos. Chem. Phys., 9, 6705-6715, https://doi.org/10.5194/acp-9-67052009, 2009.

Welti, A., Lüönd, F., Kanji, Z. A., Stetzer, O., and Lohmann, U.: Time dependence of immersion freezing: an experimental study on size selected kaolinite particles, Atmos. Chem. Phys., 12, 9893-9907, https://doi.org/10.5194/acp-12-9893-2012, 2012.

Welti, A., Kanji, Z. A., Lüönd, F., Stetzer, O., and Lohmann, U.: Exploring the Mechanisms of Ice Nucleation on Kaolinite: From Deposition Nucleation to Condensation Freezing, J. Atmos. Sci., 71, 16-36, https://doi.org/10.1175/JAS-D-12-0252.1, 2014.

Westbrook, C. D. and Illingworth, A. J.: Evidence that ice forms primarily in supercooled liquid clouds at temperatures $>-27^{\circ} \mathrm{C}$, Geophys. Res. Lett., 38, https://doi.org/10.1029/2011GL048021, 2011.

Wex, H., DeMott, P. J., Tobo, Y., Hartmann, S., Rösch, M., Clauss, T., Tomsche, L., Niedermeier, D., and Stratmann, F.: Kaolinite particles as ice nuclei: learning from the use of different kaolinite samples and different coatings, Atmos. Chem. Phys., 14, 55295546, https://doi.org/10.5194/acp-14-5529-2014, 2014.
Wex, H., Augustin-Bauditz, S., Boose, Y., Budke, C., Curtius, J., Diehl, K., Dreyer, A., Frank, F., Hartmann, S., Hiranuma, N., Jantsch, E., Kanji, Z. A., Kiselev, A., Koop, T., Möhler, O., Niedermeier, D., Nillius, B., Rösch, M., Rose, D., Schmidt, C., Steinke, I., and Stratmann, F.: Intercomparing different devices for the investigation of ice nucleating particles using Snomax $^{\circledR}$ as test substance, Atmos. Chem. Phys., 15, 14631485, https://doi.org/10.5194/acp-15-1463-2015, 2015.

Yakobi-Hancock, J. D., Ladino, L. A., and Abbatt, J. P. D.: Feldspar minerals as efficient deposition ice nuclei, Atmos. Chem. Phys., 13, 11175-11185, https://doi.org/10.5194/acp-13-11175-2013, 2013.

Zhu, C., Veblen, D. R., Blum, A. E., and Chipera, S. J.: Naturally weathered feldspar surfaces in the Navajo Sandstone aquifer, Black Mesa, Arizona: Electron microscopic characterization, Geochim. Cosmochim. Ac., 70, 4600-4616, https://doi.org/10.1016/j.gca.2006.07.013, 2006.

Zimmermann, F., Weinbruch, S., Schätz, L., Hofmann, H., Ebert, M., Kandler, K., and Worringen, A.: Ice nucleation properties of the most abundant mineral dust phases, J. Geophys. Res., 113, d23204, https://doi.org/10.1029/2008JD010655, 2008. 